\title{
The gliotransmitter ACBP controls feeding and energy homeostasis via the melanocortin system
}

\author{
Khalil Bouyakdan, ${ }^{1}$ Hugo Martin, ${ }^{2,3}$ Fabienne Liénard, ${ }^{4}$ Lionel Budry, ${ }^{1}$ Bouchra Taib, ${ }^{1}$ Demetra Rodaros, ${ }^{1}$ Chloé Chrétien, ${ }^{4}$ \\ Éric Biron, ${ }^{5}$ Zoé Husson, ${ }^{2,3,6}$ Daniela Cota, ${ }^{6}$ Luc Pénicaud, ${ }^{4,7}$ Stephanie Fulton, ${ }^{1}$ Xavier Fioramonti, ${ }^{2,3,4}$ and Thierry Alquier ${ }^{1}$ \\ 'Centre de Recherche du Centre Hospitalier de l'Université de Montréal (CRCHUM), Montreal Diabetes Research Center, and Departments of Medicine, Pathology and Cell Biology, Biochemistry, \\ Neurosciences, and Nutrition, Université de Montréal, Montreal, Quebec, Canada. ${ }^{2}$ Université de Bordeaux, INRA, NutriNeuro, Bordeaux, France. ${ }^{3}$ Bordeaux INP, NutriNeuro, Talence, France. ${ }^{4}$ Centre des \\ Sciences du Goût et de l'Alimentation, UMR 6265 CNRS, 1324 INRA, Université de Bourgogne Franche-Comté, Dijon, France. ${ }^{5}$ Faculty of Pharmacy, Université Laval and Laboratory of Medicinal Chemistry, \\ Centre de Recherche du Centre Hospitalier Universitaire de Québec (CRCHUQ), Quebec, Quebec, Canada. ${ }^{6}$ INSERM, Université de Bordeaux, Neurocentre Magendie, Physiopathologie de la Plasticité \\ Neuronale, U1215, Bordeaux, France. ${ }^{7}$ Stromalab, CNRS ERL 5311, Université de Toulouse, Université Paul Sabatier, Toulouse, France.
}

\begin{abstract}
Glial cells have emerged as key players in the central control of energy balance and etiology of obesity. Astrocytes play a central role in neural communication via the release of gliotransmitters. Acyl-CoA-binding protein-derived (ACBP-derived) endozepines are secreted peptides that modulate the GABA ${ }_{A}$ receptor. In the hypothalamus, ACBP is enriched in arcuate nucleus (ARC) astrocytes, ependymocytes, and tanycytes. Central administration of the endozepine octadecaneuropeptide (ODN) reduces feeding and improves glucose tolerance, yet the contribution of endogenous ACBP in energy homeostasis is unknown. We demonstrated that ACBP deletion in GFAP' astrocytes, but not in Nkx2.1-lineage neural cells, promoted dietinduced hyperphagia and obesity in both male and female mice, an effect prevented by viral rescue of ACBP in ARC astrocytes. $\mathrm{ACBP}^{+}$astrocytes were observed in apposition with proopiomelanocortin (POMC) neurons, and ODN selectively activated POMC neurons through the ODN GPCR but not CABA $A_{A}$, and suppressed feeding while increasing carbohydrate utilization via the melanocortin system. Similarly, ACBP overexpression in ARC astrocytes reduced feeding and weight gain. Finally, the ODN GPCR agonist decreased feeding and promoted weight loss in ob/ob mice. These findings uncover ACBP as an ARC gliopeptide playing a key role in energy balance control and exerting strong anorectic effects via the central melanocortin system.
\end{abstract}

\section{Introduction}

In the central nervous system, the hypothalamus is a key site for the detection and integration of circulating metabolic signals. In turn, the hypothalamus initiates appropriate neuroendocrine and behavioral responses to maintain energy homeostasis. In the arcuate nucleus (ARC) of the hypothalamus, 2 functionally opposing neuronal populations play a critical role in this control, the agoutirelated peptide (AgRP) neurons and proopiomelanocortin (POMC) neurons. When activated by signals of energy sufficiency including leptin and insulin, arcuate POMC neurons release $\alpha$-melanocytestimulating hormone that activates the melanocortin- 4 receptor (MC4R) and downstream anorectic and catabolic responses (1). The importance of the melanocortin system in the etiology of obesity is underscored by several lines of evidence showing that impairments in metabolic sensing in POMC neurons lead to obesity in rodents (2-6) and that mutation in the genes coding for POMC and MC4R are the most frequent form of monogenic human obesity (7).

It is now well established that glial cells exert crucial functions in the formation, activity, and adaptation of neuronal circuits. Astrocytes are closely associated with neuronal synapses to regulate syn-

Conflict of interest: The authors have declared that no conflict of interest exists. Copyright: () 2019, American Society for Clinical Investigation.

Submitted: July 9, 2018; Accepted: March 26, 2019; Published: May 13, 2019

Reference information: J Clin Invest. 2019;129(6):2417-2430.

https://doi.org/10.1172/JCI123454. aptic strength and neurotransmission. In line with these functions, studies implicate astrocytes in complex and fundamental behaviors such as breathing (8), sleeping (9), and feeding $(10,11)$.

Importantly, astrocytes have recently emerged as key players in the central response to metabolic signals and the control of energy balance (12), and obesity (13). Modulating the capacity of hypothalamic astrocytes to sense hormones and nutrients impairs glucose homeostasis (14-17) and feeding (18), and contributes to diet-induced obesity (19). Recent studies suggest that metabolites secreted by astrocytes such as lactate $(20,21)$, ketones $(22,23)$, or adenosine $(10,24)$ modulate the activity of hypothalamic neurocircuits. Whether and by which mechanisms astrocyte-derived signals affect the melanocortin system and downstream catabolic responses remain essentially unknown.

Astrocytes also release peptidic gliotransmitters (gliopeptides) (25), yet their contribution to the hypothalamic control of energy homeostasis is entirely unknown. Acyl-CoA-binding protein (ACBP) is a highly conserved peptide secreted by cultured astrocytes (26) in response to various signals $(27,28)$. ACBP, also known as diazepam binding inhibitor (DBI), was initially identified in the brain as a modulator of GABA signaling by inhibition of the binding of diazepam on the $\mathrm{GABA}_{\mathrm{A}}$ receptor (29). Once secreted, ACBP is cleaved to generate endozepines including the octadecaneuropeptide (ODN) (30). Our laboratory and others have shown that ACBP is expressed throughout the brain, with a particular enrichment in hypothalamic ependymocytes, tanycytes, 
and astrocytes (31-33). Importantly, intracerebroventricular (i.c.v.) administration of ODN reduces food intake (34) and improves glucose tolerance in rodents (33). Despite these findings, the impact of endogenous ACBP-mediated gliotransmission on feeding, energy metabolism, and hypothalamic neuronal activity has not been studied. Here we used multiple gene interventions, $\mathrm{Ca}^{2+}$ imaging, and electrophysiology to reveal the unique role of ACBP as a gliopeptide in the ARC of the hypothalamus robustly controlling feeding and energy metabolism via the melanocortin pathway.

\section{Results}

Acbp gene expression is regulated by fasting but not high-fat feeding in a circadian manner. ACBP is the precursor of the anorectic peptide ODN; thus we tested whether its expression in the hypothalamus was dependent on the time of the day and nutritional status. Acbp mRNA level in ARC microdissections was maximal at zeitgeber time 6 (ZT6; middle of the light cycle) and gradually decreased to its lowest level at ZT18 (Supplemental Figure 1A; supplemental material available online with this article; https://doi.org/10.1172/ JCI123454DS1). Acbp expression was decreased by fasting at ZT6 but not ZT18, while pomc levels were reduced at both time points (Supplemental Figure 1, B and C). Finally, acbp gene expression in the ARC was not affected by 3, 7, or 42 days of high-fat feeding (Supplemental Figure 1, D and E). Together, these findings demonstrate that $a c b p$ is regulated in a circadian manner by food deprivation but not caloric excess and overweight.

Astroglial ACBP deficiency promotes diet-induced obesity. We then sought to identify the role of astroglial ACBP in energy balance using a cell-specific gene knockout approach. ACBP $P^{f / f l} G F A P$ Cre $\left(\mathrm{ACBP}{ }^{\mathrm{GFAP}} \mathrm{KO}\right)$ mice were generated as we previously described (31). ACBP ${ }^{\mathrm{GFAP}} \mathrm{KO}$ mice were devoid of ACBP expression in glial fibrillary acidic protein-positive $\left(\mathrm{GFAP}^{+}\right)$astrocytes and some tanycytes of the ARC and median eminence as compared with littermate control mice (Supplemental Figure 2A). Moreover, as we previously reported (31), we did not observe ACBP expression in the ependymal layer of the median eminence. Acbp gene expression in ARC microdissections (including the median eminence and ependymal layer) derived from chow- and high fat-fed ACBP ${ }^{\mathrm{GFAP}} \mathrm{KO}$ and $G F A P^{\text {Cre }}$ control mice (ACBP ${ }^{\mathrm{GFAP}} \mathrm{WT}$ ) confirmed $a c b p$ gene deletion (Supplemental Figure 2B). Residual acbp expression (10\%) likely represents $a c b p$ expression in neurons (32) and GFAP-negative astrocytes (Supplemental Figure 2A). Expectedly, acbp expression was reduced by half in $A C B P^{f /+} G F A P^{\text {Cre }}$ (ACBP ${ }^{\text {GFAP }}$ HET) (Supplemental Figure 2B).

Body weight was significantly increased at week 10 while energy expenditure (light phase) was reduced in chow-fed ACBP ${ }^{\mathrm{GFAP}} \mathrm{KO}$ male mice without changes in cumulative food intake, respiratory exchange ratio (RER), and locomotor activity as compared with controls (Supplemental Figure 2, C-G). Based on accumulating evidence suggesting a key role of hypothalamic astrocytes in feeding in response to leptin $(18,35)$ and fatty acids $(19,22)$, we tested whether astroglial ACBP is involved in the anorectic action of these signals. The anorectic response to central leptin was similar in ACBP ${ }^{\text {GFAP }} \mathrm{KO}$ males and control littermates (Supplemental Figure $2 \mathrm{H}$ ). In contrast, the anorectic effect of central oleate was absent in ACBP ${ }^{\text {GFAP }}$ KO males compared to controls (Supplemental Figure 2I). During a high-fat regimen, astroglial ACBP deficiency considerably enhanced the response to diet-induced obesity in both male and female ACBP ${ }^{\mathrm{GFAP}} \mathrm{KO}$ mice (Figure 1, A-D). Weight gain and food intake were increased in $A C B P^{G F A P} \mathrm{KO}$ male mice as of week 3 of the 16-week high-fat diet (HFD) regimen (Figure 1, A and B). Correspondingly, ACBP ${ }^{\mathrm{GFAP}}$ HET male mice showed a less pronounced response to high-fat feeding, suggesting a gene dosage effect. In male and female ACBP ${ }^{\mathrm{GFAP}} \mathrm{KO}$ mice, weekly food intake was increased before the onset of overweight, suggesting that hyperphagia plays a causal role in the obesity-prone phenotype (insets, Figure 1, B and D). Increased body weight gain in male $\mathrm{ACBP}^{\mathrm{GFAP}} \mathrm{KO}$ mice was not associated with changes in RER or locomotor activity (Supplemental Figure 3, A and B) but was associated with a trend toward reduced energy expenditure after 6 weeks (not shown) or 16 weeks of HFD (Supplemental Figure 3C). In contrast, female $\mathrm{ACBP}^{\mathrm{GFAP}} \mathrm{KO}$ mice had higher RER (Supplemental Figure 3D) without changes in activity and energy expenditure (Supplemental Figure 3, E and F). ACBP ${ }^{\mathrm{GFAP}} \mathrm{KO}$ mice had greater fat mass (Figure 1E and Supplemental Figure 3G), with subcutaneous fat increased in males (Figure $1 \mathrm{~F}$ ) and intraperitoneal fat increased in females (Supplemental Figure 3G). Increase in fat mass was accompanied by higher plasma leptin levels (Figure 1G). A comparable enhanced weight gain in response to HFD was also observed in female mice on a mixed BL/6J-Bom genetic background (Supplemental Figure $3 \mathrm{H})$. Finally, $\mathrm{ACBP}^{\mathrm{GFAP}} \mathrm{KO}$ male mice did not exhibit changes in glucose tolerance (Figure 1, H and I), which could be explained by a compensatory increase in insulin secretion during the glucose tolerance test (Figure 1J) suggestive of an insulin resistance state.

We previously reported ACBP expression in discrete ARC neurons. In addition, ACBP is highly expressed in ependymocytes and tanycytes (Supplemental Figure 2A and refs. 32, 33), both of which are targeted by ACBP ablation in our KO model (Supplemental Figure 2A and ref. 31). Thus, it is possible that ACBP loss of function in ependymocytes and/or tanycytes may contribute to the observed phenotype. To verify this, $A C B P^{f / f l}$ mice were crossed with $N k x 2.1^{\text {Cre }}$ mice ( $\mathrm{ACBP}^{\mathrm{Nkx} 2.1} \mathrm{KO}$ ), in which Cre is driven by Nkx2.1, a promoter expressed in hypothalamic ependymocytes, tanycytes, and neurons $(36,37)$. As expected, ACBP protein expression was reduced in cells lining the third ventricle (Supplemental Figure 4A), and $a c b p$ mRNA decreased by $64 \%$ in ARC microdissections (Supplemental Figure 4B). However, both male and female ACBP ${ }^{\mathrm{Nkx} 2.1} \mathrm{KO}$ mice on an HFD had similar body weight gain and cumulative food intake compared with control littermates (Supplemental Figure 4, C and D), suggesting that ACBP deficiency in hypothalamic ependymocytes, tanycytes, and neurons does not influence energy balance in obesogenic conditions. Together, these results imply that pan-brain astroglial ACBP deficiency increases the susceptibility to overweight in chow-fed mice and to diet-induced hyperphagia and obesity.

Acbp gene rescue in ARC astrocytes prevents diet-induced obesity. Our results suggest that astroglial ACBP plays an important role in high-fat feeding and body weight regulation, yet the pan-astroglial KO model does not permit identification of the brain region(s) involved. Based on a previous report showing that administration of the ODN C-terminal octapeptide in the ARC exerts anorectic effects similar to those of i.c.v. administration (33) and on the strong ACBP expression in the ARC $(32,33)$, we designed an adeno- 
A

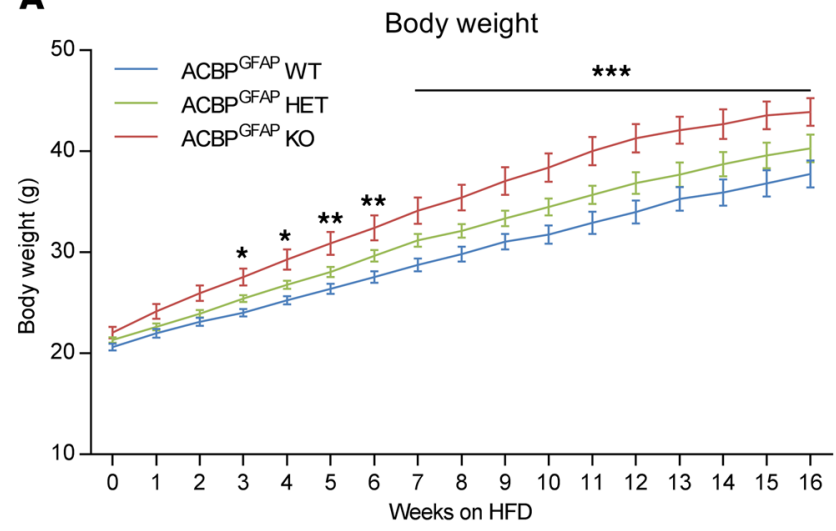

C

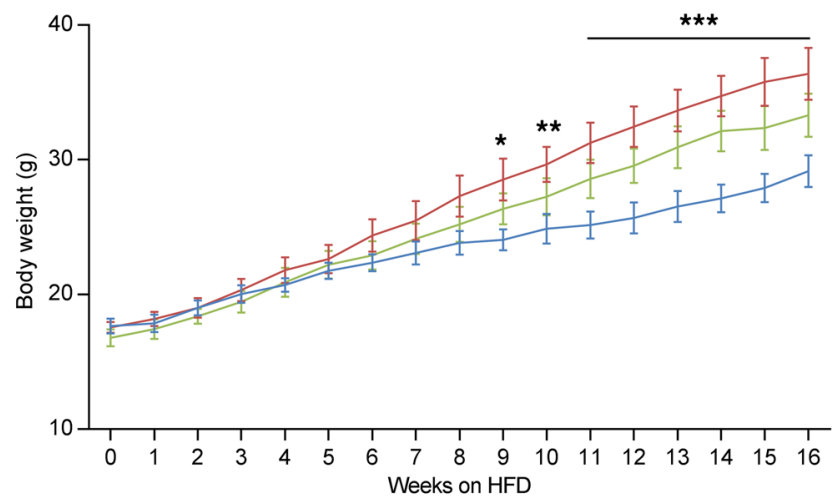

B

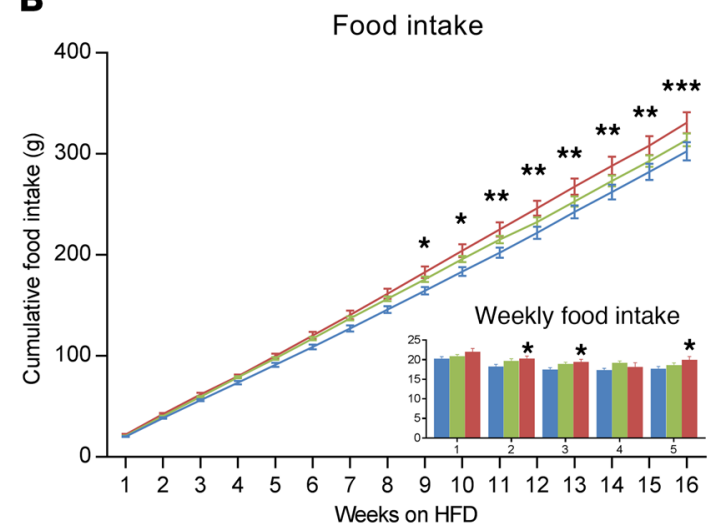

D

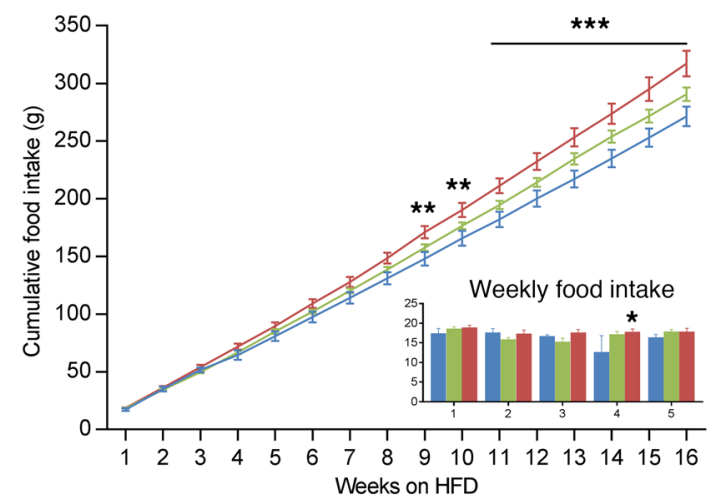

E

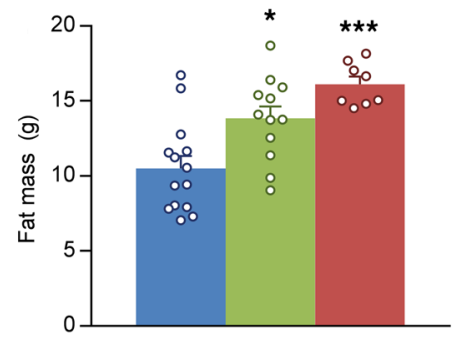

$\mathbf{F}$

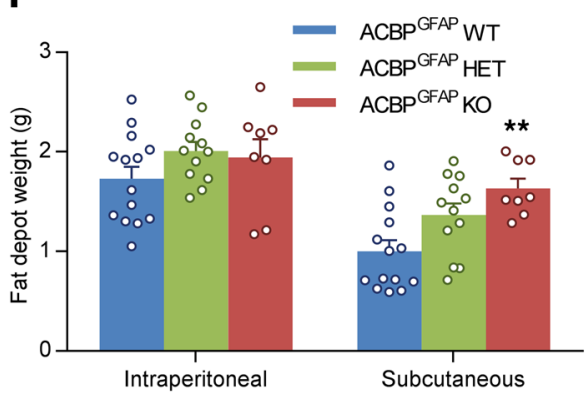

I

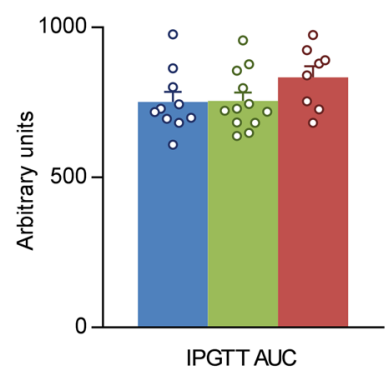

IPGTT AUC
G

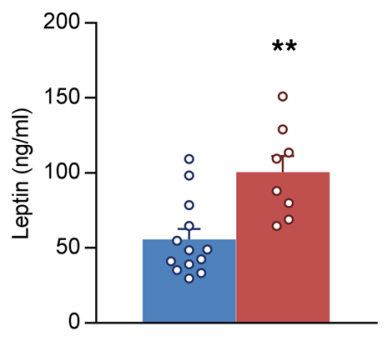

H

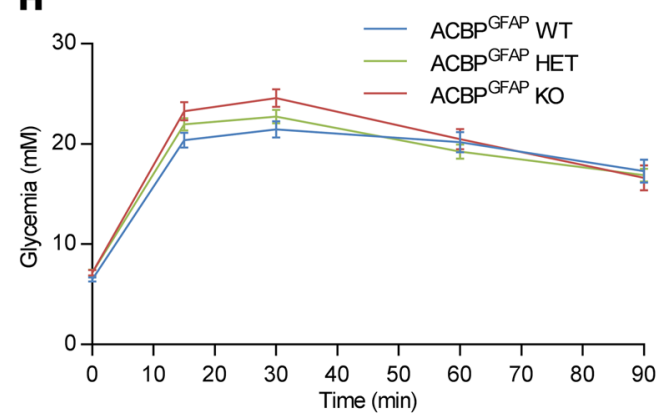

\section{J}

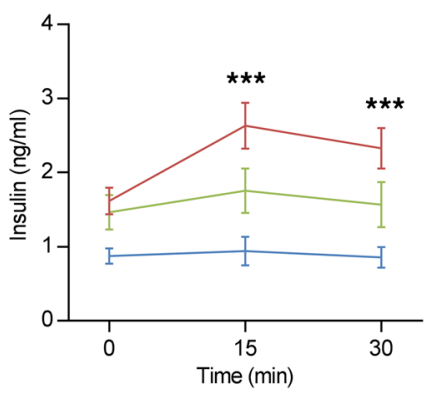

Figure 1. Pan-brain astroglial ACBP deficiency promotes diet-induced obesity. (A-D) Body weight and cumulative food intake of male (A and B) and female (C and D) ACBP GFAP WT, HET, and KO mice fed with an HFD during 16 weeks. Insets in $\mathbf{B}$ and $\mathbf{D}$ represent average weekly food intake. (E-G) Fat mass (E), fat depot weights (F), and fasting plasma leptin levels (G). (H and I) Intraperitoneal glucose tolerance test (IPGTT; $1.5 \mathrm{~g} / \mathrm{kg}$ ) (H) and area under the curve (AUC) (I). (J) Plasma insulin levels during the IPGTT. ${ }^{*} P<0.05,{ }^{*} P<0.01,{ }^{* *} P<0.001$ compared with control littermates, 2 -way ANOVA with Bonferroni post hoc test (A-D and J). ${ }^{*} P<0.05$, ${ }^{* *} P<0.01,{ }^{* *} P<0.001$ compared with controls, 1 -way ANOVA with Bonferroni post hoc test (E and $\left.\mathbf{F}\right)$. ${ }^{*} P<0.01$ compared with controls, Student's $t$ test (G). $n=8-15$ for male mice (A, B, and E-J) and 6-7 for female mice (C and $\left.\mathbf{D}\right)$. 
$\mathbf{A}$

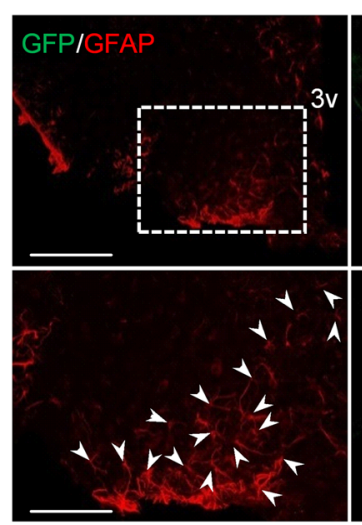

C

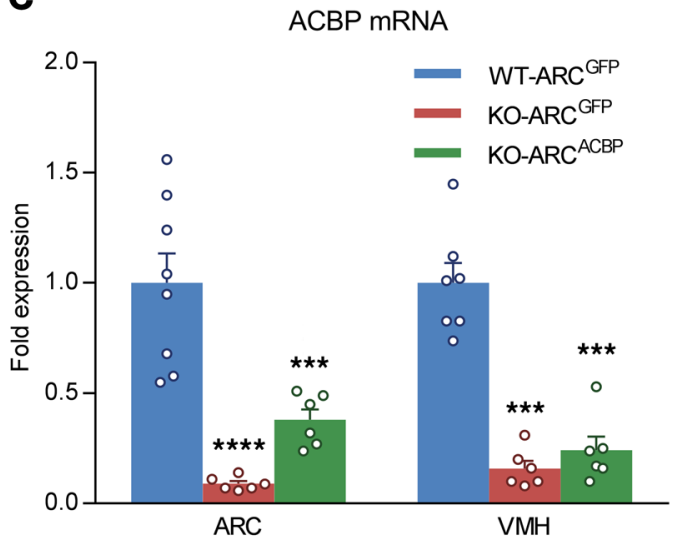

$\mathbf{F}$

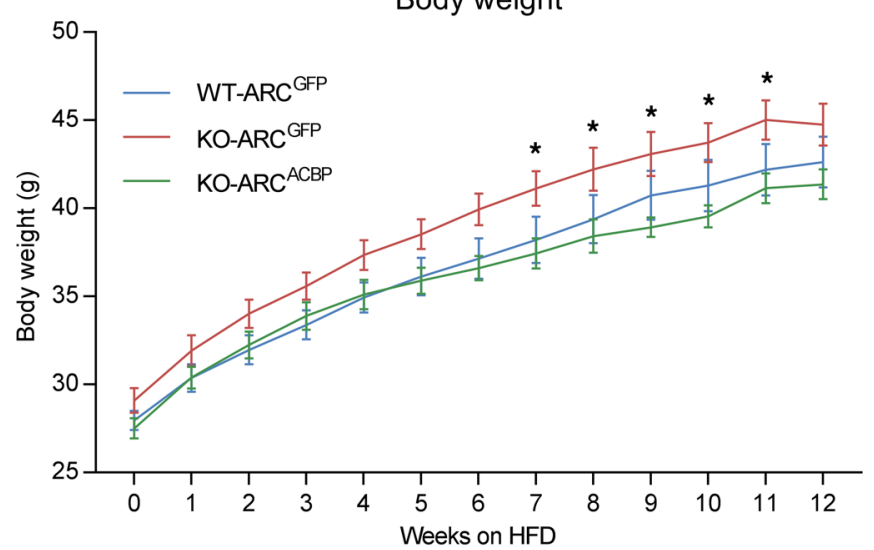

D
B
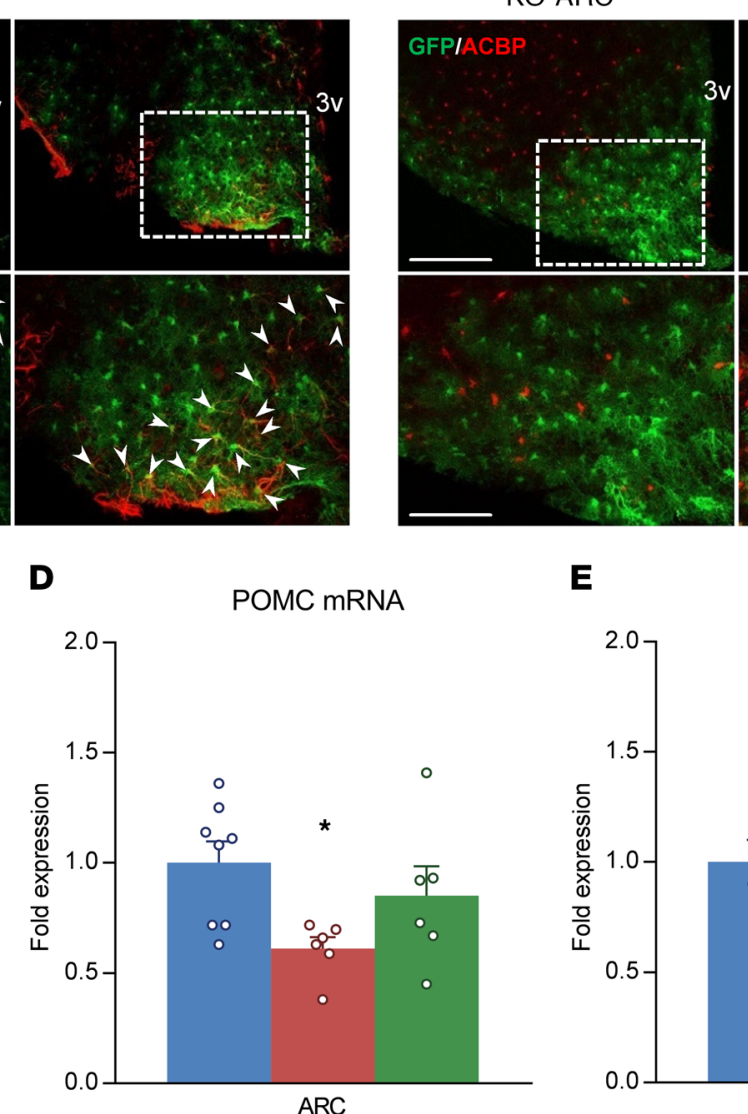

E

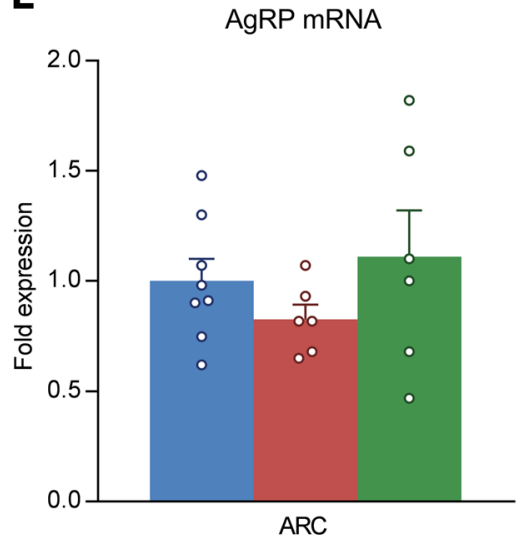

G

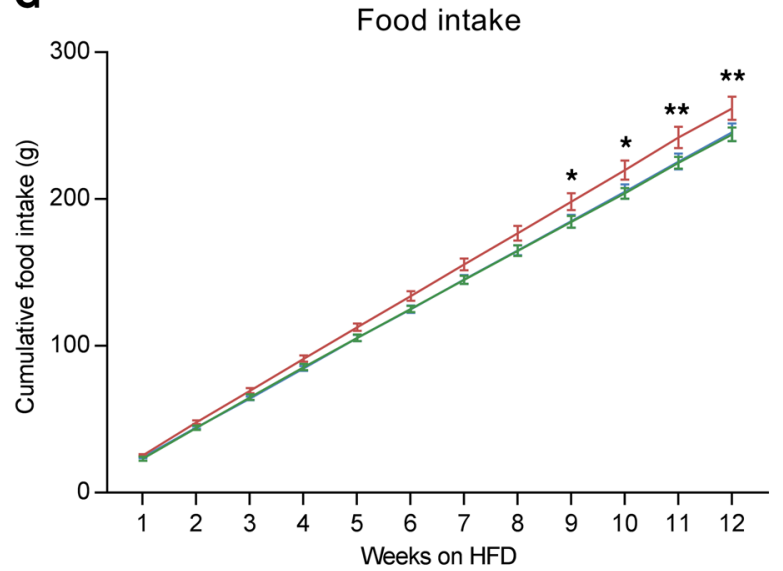

Figure 2. Genetic rescue of ACBP in GFAP+ astrocytes of the ARC prevents diet-induced obesity. (A and B) Immunostaining of GFAP (red) and GFP (green) in GFAP-Cre mice injected with AAV expressing GFP under the control of the GFAP promoter in the ARC (A) and ACBP (red) and GFP (green) in ACBPGFAP KO mice injected with AAV expressing GFP (left, KO-ARC CFP) or ACBP (right, KO-ARC ${ }^{A C B P}$ ) in the ARC (B). White arrowheads indicate cells coexpressing GFAP and GFP (A) and cells coexpressing ACBP and GFP (B). Scale bars: $100 \mu \mathrm{m}$ in top panels and $50 \mu \mathrm{m}$ in zoomed panels (bottom). Representative images from 3 different mice. $3 \mathrm{v}$, third ventricle. (C-E) Acbp expression measured by quantitative PCR in ARC and VMH microdissections (C), and pomc (D) and $\operatorname{agrp~(E)~mRNA~levels~in~ARC~microdissections.~}{ }^{*} P<0.05,{ }^{* * *} P<0.001,{ }^{* * *} P<0.0001$ compared with WT-ARC ${ }^{\text {CFP }}$, 1-way ANOVA with Bonferroni post hoc test, $n=6$-9. (F and $\mathbf{G})$ Body weight $(\mathbf{F})$ and cumulative food intake (C) in animals fed with an HFD during 12 weeks. ${ }^{*} P<0.05,{ }^{* *} P<0.01 \mathrm{KO}-\mathrm{ARC}{ }^{\mathrm{ACBB}}$ compared with KO-ARC GFP, 2-way ANOVA with Bonferroni post hoc test, $n=6-9$.

associated virus (AAV) to rescue ACBP expression selectively in $\mathrm{GFAP}^{+}$astrocytes of the ARC of $\mathrm{ACBP}^{\mathrm{GFAP}} \mathrm{KO}$ mice (KO-ARC ${ }^{\mathrm{ACBP}}$ ) (38). Control mice (GFAP ${ }^{\mathrm{Cre}}$ and $\mathrm{ACBP}^{\mathrm{GFAP}} \mathrm{KO}$ ) were injected with a GFP-expressing AAV (Figure 2, A and B) (WT-ARC ${ }^{\text {GFP }}$ and KO-
$\mathrm{ARC}^{\mathrm{GFP}}$, respectively). Expression of ACBP was partially restored in ARC astrocytes of KO-ARC ${ }^{A C B P}$ mice as compared with KO-ARC ${ }^{\text {GFP }}$ mice, but not in ependymocytes and tanycytes (Figure 2B). This partial rescue of $a c b p$ in the ARC (Figure $2 \mathrm{C}$ ) prevented the decrease in 


\section{A}

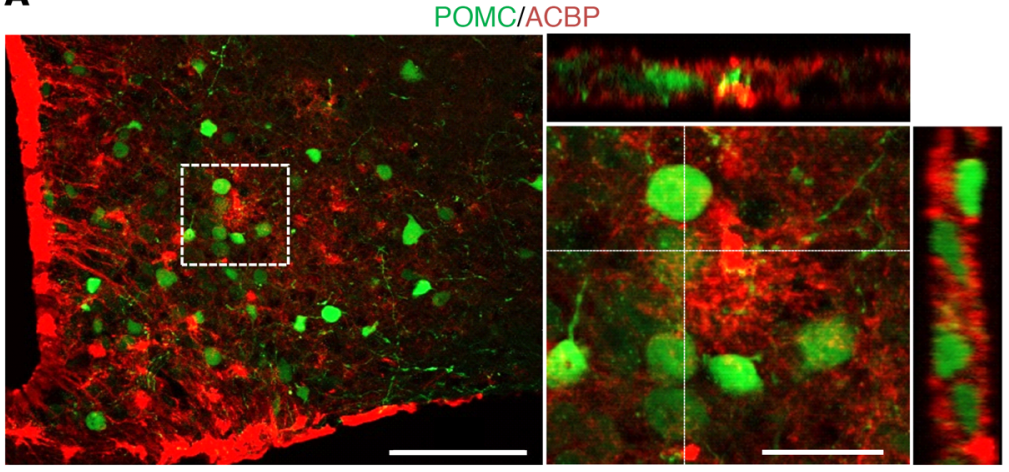

B

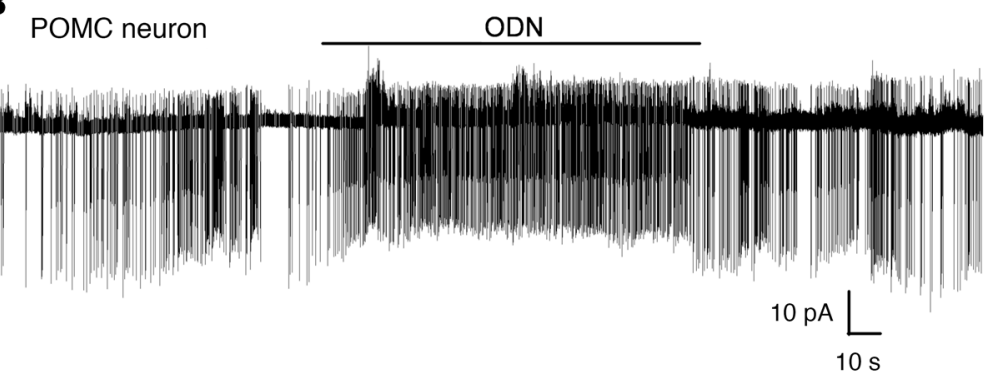

C

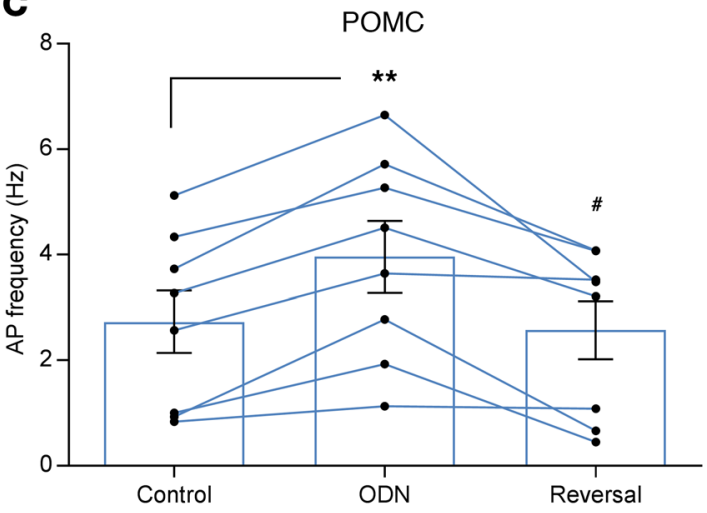

D

non-POMC neuron ODN

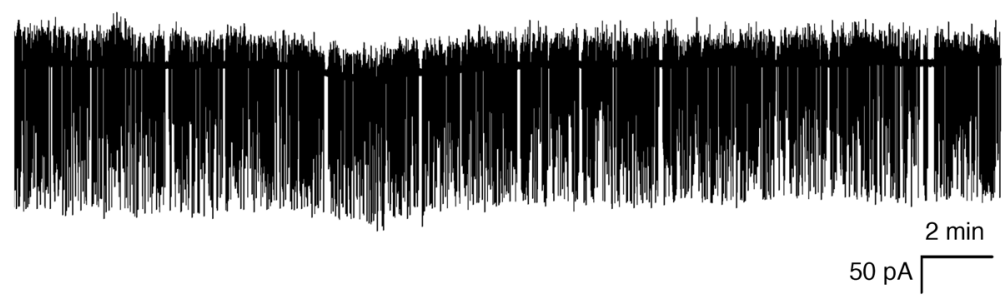

E

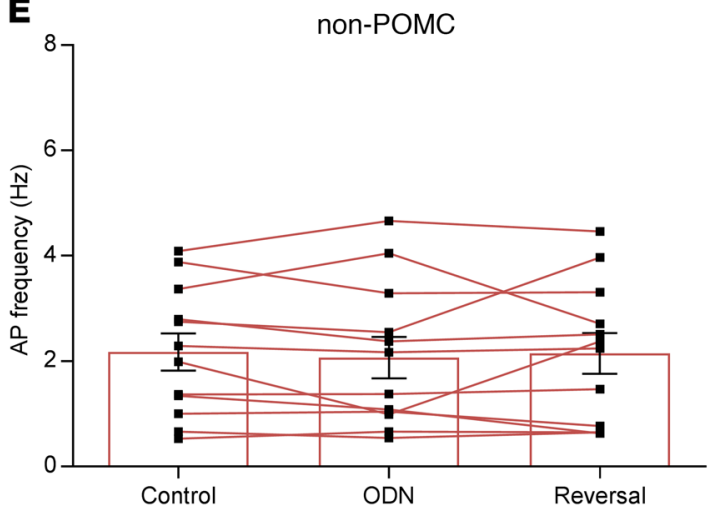

Figure 3. ODN selectively activates POMC neurons in the ARC. (A) Immunostaining of ACBP+ astrocytes (red) in close proximity to ARC POMC-eGFP neurons (green). Boxed area is represented with orthogonal projections. Scale bar: $100 \mu \mathrm{m}$ in left panel and $25 \mu \mathrm{m}$ in right panel. Representative images from 3 different mice. (B-E) Representative trace and quantification of action potential (AP) frequency in ARC POMC (B and C; $n=8$ neurons from 7 mice) or non-POMC ( $\mathbf{D}$ and $\mathbf{E} ; n=12$ neurons from 7 mice) neurons in the presence or absence of $1 \mathrm{nM} \mathrm{ODN.}{ }^{* *} P<0.001$ compared with control and ${ }^{\#} P<0.05$ compared with ODN, 1-way ANOVA with repeated measures with Bonferroni post hoc test.

pomc mRNA expression without affecting agrp mRNA levels (Figure 2, D and E) and the diet-induced obesity and hyperphagia phenotype (Figure 2, F and G). These findings strongly suggest that ACBP in ARC astrocytes, but not in tanycytes, ependymocytes, or extraARC astrocytes, is important for controlling energy balance.

Central effects of $O D N$ on energy homeostasis rely on the melanocortin system. Our findings that astroglial ACBP in the ARC modulates high-fat feeding and body weight and a report that the anorectic effect of ODN can be offset by a melanocortin-3/4 receptor antagonist (33) suggest that the catabolic effects of ACBP could rely on the melanocortin system. First, we observed that several
$\mathrm{ACBP}^{+}$astrocytes were in close proximity to POMC neurons (Figure 3A). Second, using patch-clamp electrophysiological recordings in brain slices from POMC-eGFP mice, we found that ODN considerably increased the action potential (AP) frequency of all POMC neurons tested without affecting the firing rate of neighboring non-POMC neurons within the ARC (Figure 3, B-E).

To determine whether the anorectic and metabolic effects of central ODN are dependent on the melanocortin system, ODN was administered i.c.v. in obese MC4R-KO mice and control WT mice. The dose of ODN was chosen based on a previous study in mice (34). Intracerebroventricular ODN decreased food intake in WT 

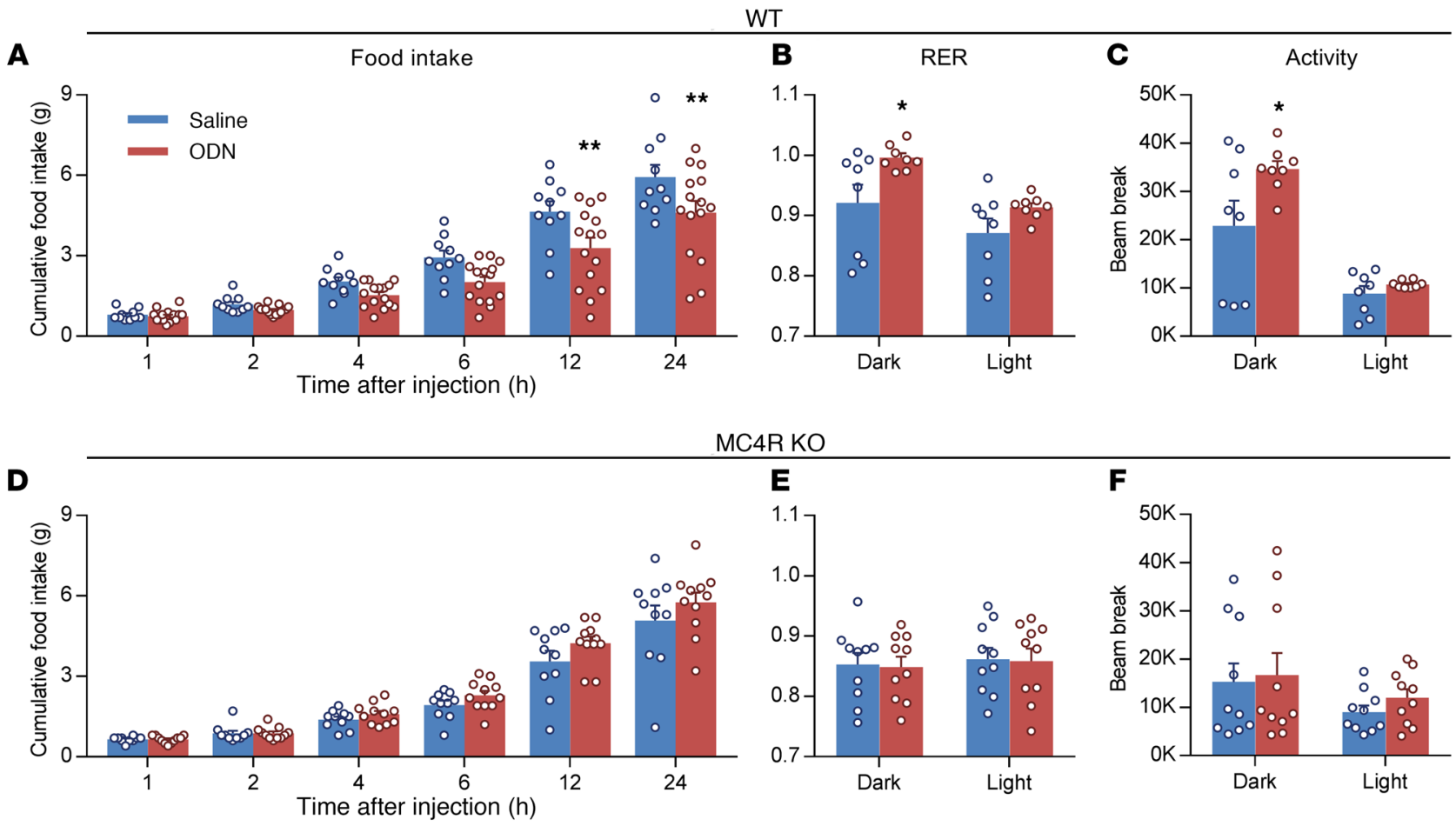

MC4R KO
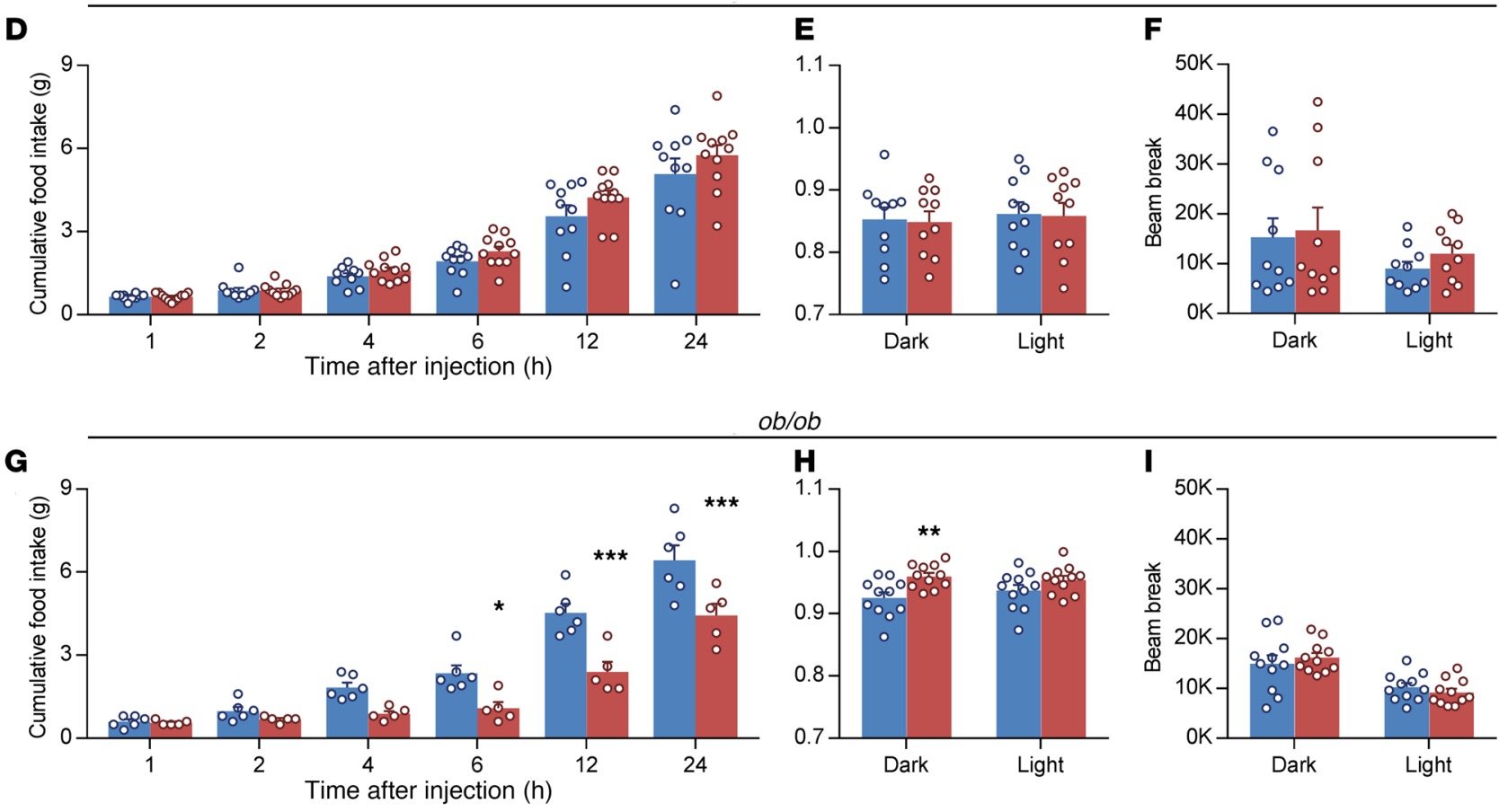

$a b / o b$

$\mathbf{J}$ ACBP mRNA

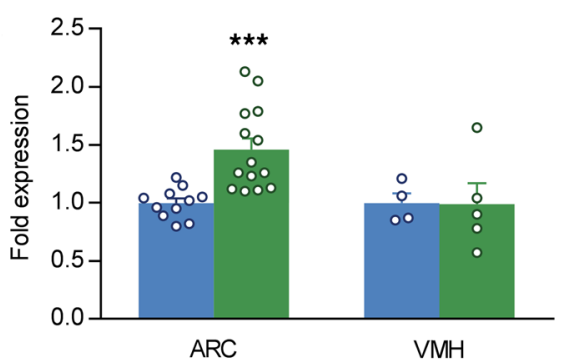

M

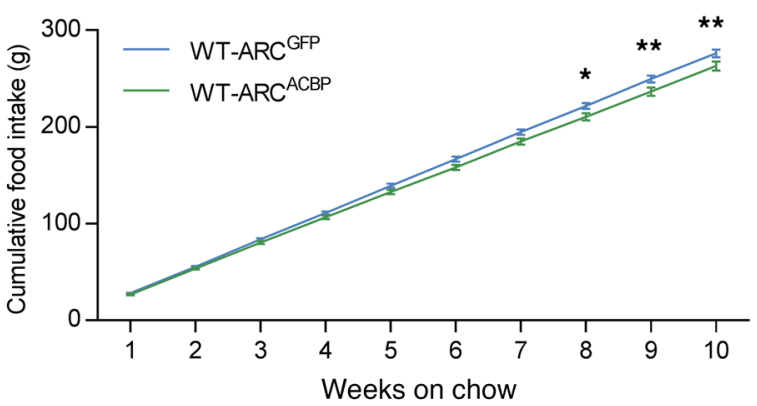

$\mathbf{K}$
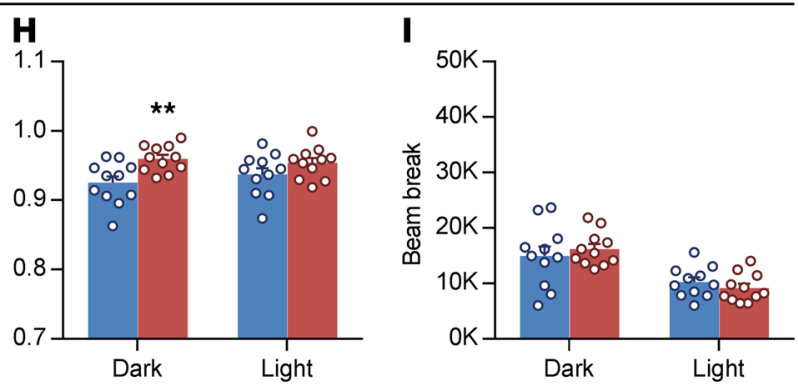

POMC mRNA

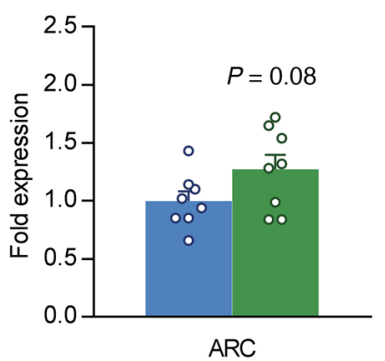

$\mathbf{L}$

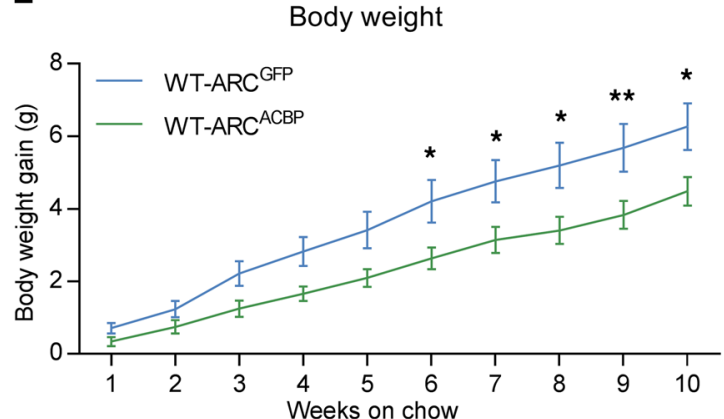


Figure 4. Central effects of ODN on energy homeostasis rely on the melanocortin system. (A-I) Cumulative food intake of [57BL/6] WT ( $n=10-15)$ (A), MC4R-KO ( $n=10-11)$ (D), and ob/ob $(n=5-6)$ (C) overnight-fasted (16 hours) male mice following i.c.v. administration of $100 \mathrm{ng}$ of ODN or saline control. RER and locomotor activity in C57BL/6] WT (B and C), MC4R-KO ( $\mathbf{E}$ and $\mathbf{F}$ ), and $o b / o b$ ( $\mathbf{H}$ and $\mathbf{I}$ ) mice measured in CLAMS metabolic cages during 24 hours following i.c.v. ODN or saline after 24 hours of acclimation. ${ }^{*} P<0.05$, ${ }^{* *} P<0.01,{ }^{* * *} P<0.001$ compared with saline controls, 2-way ANOVA with Bonferroni post hoc test. (J and $\mathbf{K})$ Acbp expression measured by quantitative PCR in ARC $(n=11-14)$ and VMH $(n=4-5)$ microdissections $(\mathrm{J})$ and pomc in ARC microdissections $(n=8)(\mathrm{K})$ from [57BL/6] WT male mice injected bilaterally in the ARC with AAV expressing GFP (WT-ARC ${ }^{\text {GFP }}$ ) or ACBP (WT-ARC ${ }^{A C B P}$ ) under the control of the GFAP promoter. ${ }^{* *} P<$ 0.001 compared with WT-ARC CFP , Student's $t$ test. ( $\mathbf{L}$ and $\mathbf{M}$ ) Body weight gain (L) and cumulative food intake (M) in WT-ARC CFP and WT-ARC ${ }^{A C B P}$ mice $(n=12-15) .{ }^{*} P<0.05,{ }^{*} P<0.01$ compared with WT-ARC CFP, 2 -way ANOVA with Bonferroni post hoc test.

mice, an effect that lasted up to 24 hours (Figure 4A). In addition, ODN significantly increased RER and locomotor activity (Figure $4, \mathrm{~B}$ and $\mathrm{C})$, without affecting energy expenditure (5.05 \pm 0.16 vs. $5.12 \pm 0.29 \mathrm{kcal}, n=8$ per group, $P=0.8$ ). The effects of central ODN were completely absent in MC4R-KO mice (Figure 4, D-F). To test whether the ineffectiveness of i.c.v. ODN was specific to this genetic model of obesity, similar experiments were performed in obese $o b / o b$ mice, in which the melanocortin system is functional. Similarly to what we observed in WT mice, i.c.v. ODN reduced feeding and increased RER in $o b / o b$ mice compared with controls (Figure 4, G-I). To validate the regional specificity of ODN anorectic action, we used a viral strategy to selectively overexpress ACBP

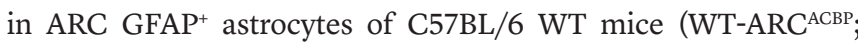
Figure $4 \mathrm{~J}$ ). In a consistent manner, we found that ACBP overexpression in $\mathrm{GFAP}^{+}$astrocytes of the ARC (Figure 4J) led to a trend toward increased pomc mRNA levels (Figure $4 \mathrm{~K}$ ) and was sufficient to reduce body weight gain and cumulative food intake over 10 weeks in chow-fed mice (Figure $4, \mathrm{~L}$ and $\mathrm{M}$ ). Together, these findings strongly suggest that the anorectic and metabolic effects of ACBP and its derived peptide ODN are mediated via the ARC melanocortin system.

ODN activates POMC neurons through a $G A B A_{A}$-independent but ODN GPCR-dependent mechanism. ODN has been shown to act as a negative allosteric modulator of the GABA receptor (39). Importantly, POMC neurons of the ARC receive strong inhibitory GABAergic inputs from neighboring neurons (40, 41), suggesting that ODN-induced POMC neuron activation could be due to inhibition of GABAergic inputs. Thus, the frequency and amplitude of spontaneous inhibitory postsynaptic currents (sIPSC) were measured onto POMC and non-POMC neurons in brain slices from POMC-eGFP mice (42). ODN significantly decreased sIPSC frequency onto POMC and non-POMC neurons (Figure 5, A and B) without affecting sIPSC amplitude (Figure 5C), showing that ODN inhibits GABAergic inputs on ARC neurons. Importantly, these findings suggest that the decrease in GABA input is not sufficient to increase neuron activity and, thus, that the selective activation of POMC neurons by ODN (Figure 3, B-E) is independent of the $\mathrm{GABA}_{\mathrm{A}}$ receptor. To confirm this, brain slices were pretreated with $\mathrm{GABA}_{\mathrm{A}}$ inhibitors to block inhibitory inputs onto POMC neurons. In these conditions, ODN was still able to increase action potential frequency of POMC neurons, suggesting that ODN activates these neurons independently of its action on inhibitory inputs and thus implicates another receptor (Figure 5, D and E).

The second potential mechanism of action of ODN implicates the ODN G protein-coupled receptor (GPCR) coupled to phospholipase $\mathrm{C}$ and $\mathrm{Ca}^{2+}(43,44)$. Although the ODN GPCR remains unidentified, cyclic analogs of ODN were designed based on the peptide sequence of ODN and selected for their agonist or antagonist properties (44). Application of the antagonist of ODN GPCR (cDLOP) suggested that the anorectic action of i.c.v. ODN is mediated through the unidentified GPCR (34). Thus, we tested whether activation of the ODN GPCR was sufficient to activate POMC neurons and reduce feeding. First, we found that treatment with the ODN GPCR agonist (cOP) increased the firing activity of POMC neurons (Figure 5F and Supplemental Figure 5A), without affecting the firing rate of neighboring non-POMC neurons in the ARC (Supplemental Figure 5, B and C). $\mathrm{Ca}^{2+}$ imaging was performed in freshly dissociated hypothalamic neurons in culture, which are isolated from each other (no dendrites and axons) (Supplemental Figure 5D), ruling out GABAergic inputs (45). Using this model, we observed that ODN increased intracellular $\mathrm{Ca}^{2+}$ oscillations in approximately $10 \%$ of the neurons tested $(9.5 \% \pm 1.5 \%$; Supplemental Figure $5 \mathrm{E})$, a percentage compatible with the proportion of POMC neurons in mediobasal hypothalamus culture. Importantly, the ODN GPCR antagonist CDLOP reduced both the number of ODN-responsive neurons $(5 \% \pm$ $1.7 \%, P<0.05$, Student's $t$ test) and the amplitude of ODN response (Supplemental Figure 5, E-G), suggesting that ODN-induced neuronal activation is dependent on the ODN GPCR. Importantly, this was confirmed by electrophysiological recordings showing that the activation of POMC neurons by ODN in the presence of GABA inhibitors was reversed by the ODN receptor antagonist cDLOP (Supplemental Figure 5, H and I). Next, we observed that i.c.v. injection of the ODN GPCR agonist cOP decreased food intake after a fast (Figure 5G). Finally, daily i.c.v. administration of the ODN GPCR agonist reduced feeding and body weight in $o b / o b$ mice (Figure 5, H and I). These results strongly suggest that ODN-induced POMC neurons' activation and anorectic responses are mediated by the unidentified ODN GPCR and that activation of the receptor promotes weight loss in obese mice.

\section{Discussion}

Astrocytes not only play a central role in the energy requirements of the brain but also produce and release gliotransmitters that modulate neural communication and play key roles in cognitive function (46) and behavior (47).

The present study identified the gliopeptide ACBP and its product ODN, commonly referred to as endozepines, as important hypothalamic regulators of energy balance via direct modulation of the melanocortin system. ACBP ablation in astrocytes led to increased susceptibility to diet-induced hyperphagia and obesity, while viral-mediated restoration of ACBP in ARC GFAP $\mathrm{AR}^{+}$ astrocytes was sufficient to prevent this effect. Our results further show that the anorectic action of endozepines is mediated by direct activation of POMC neurons and the downstream melanocortin pathway via the ODN GPCR, whose activation reduced body weight and feeding in obese mice. Collectively, our results suggest that GPCR-mediated activation of POMC neu- 
A

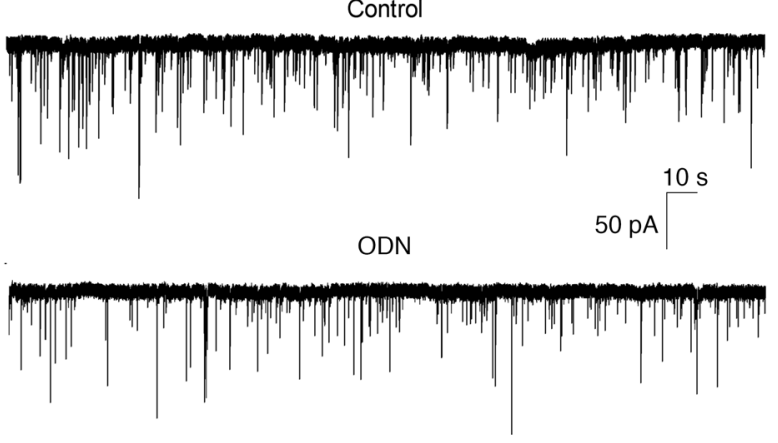

D

$20 \mathrm{pA} \stackrel{1 \mathrm{~min}}{\square}$

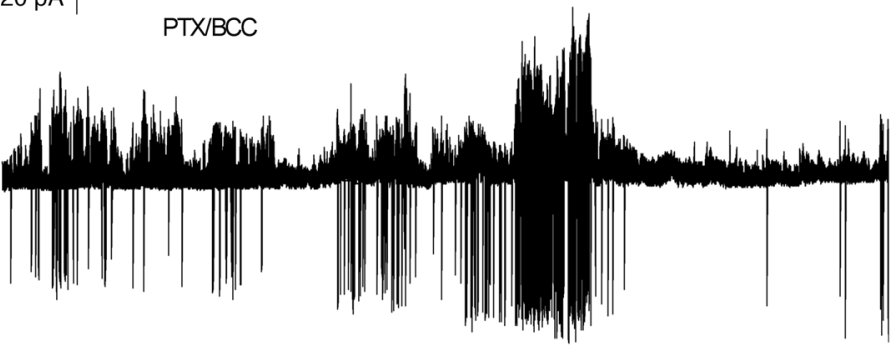

$\mathbf{F}$

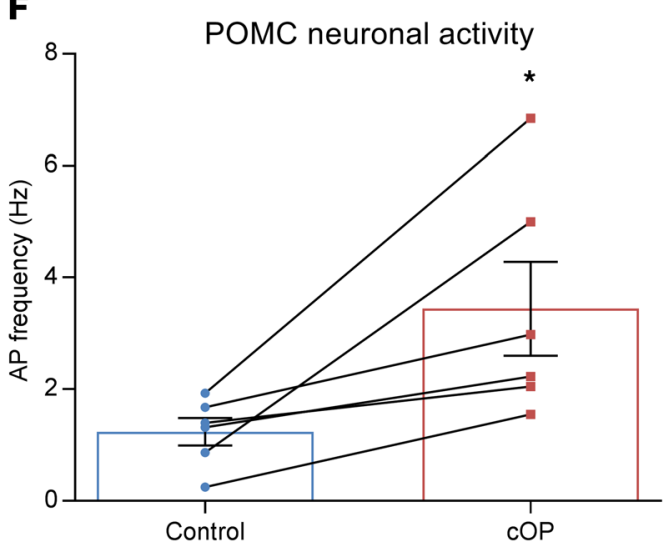

H

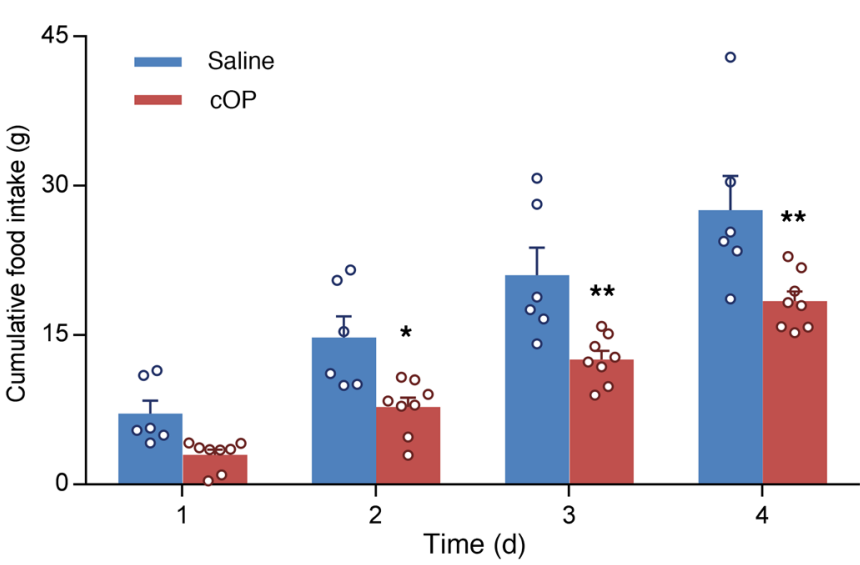

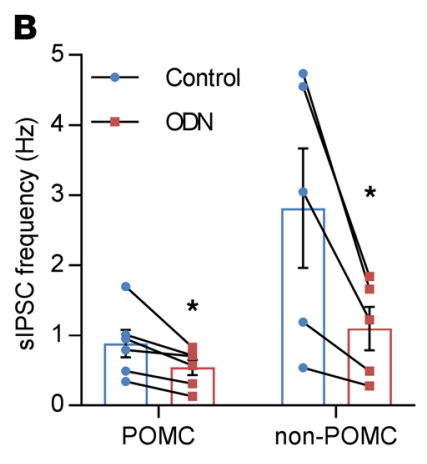

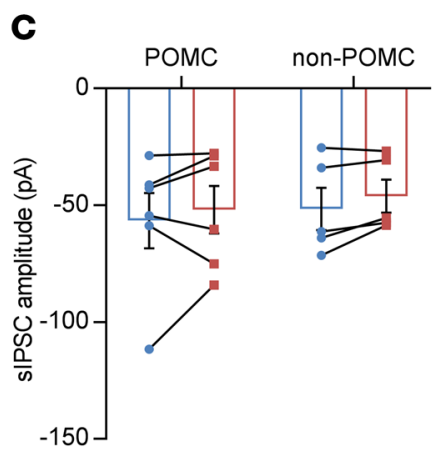

E

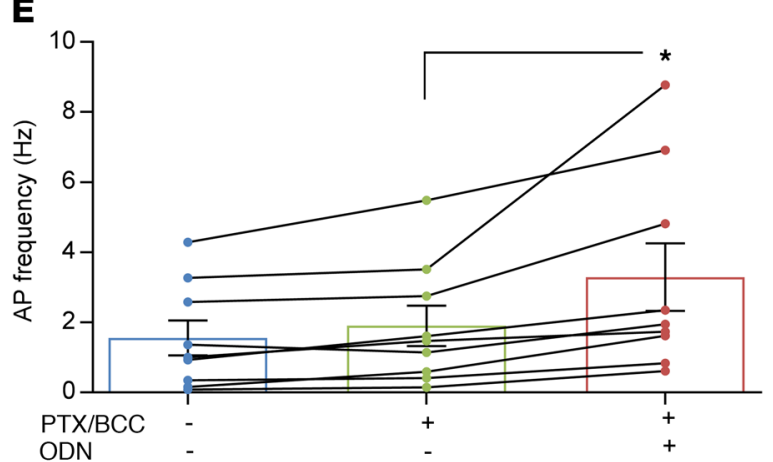

G

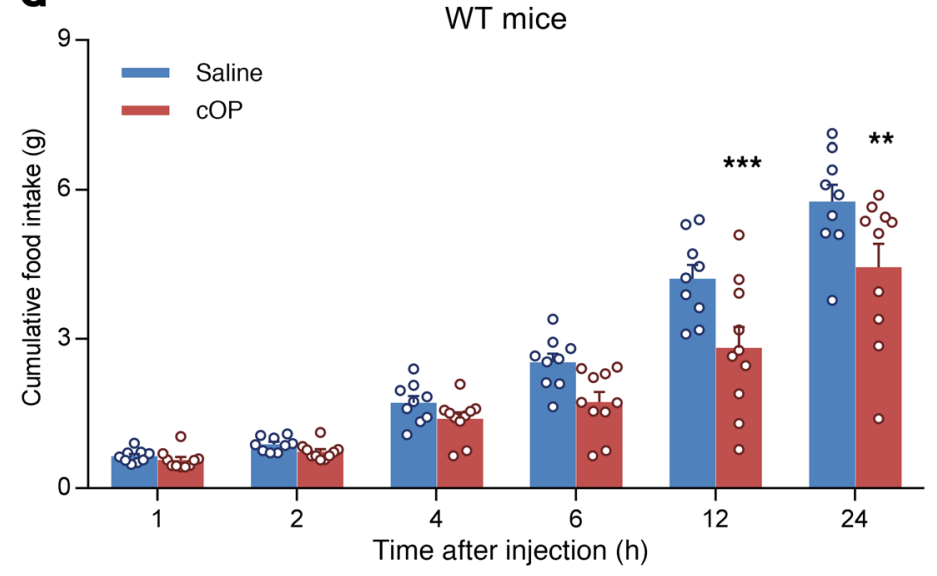

I ob/ob mice

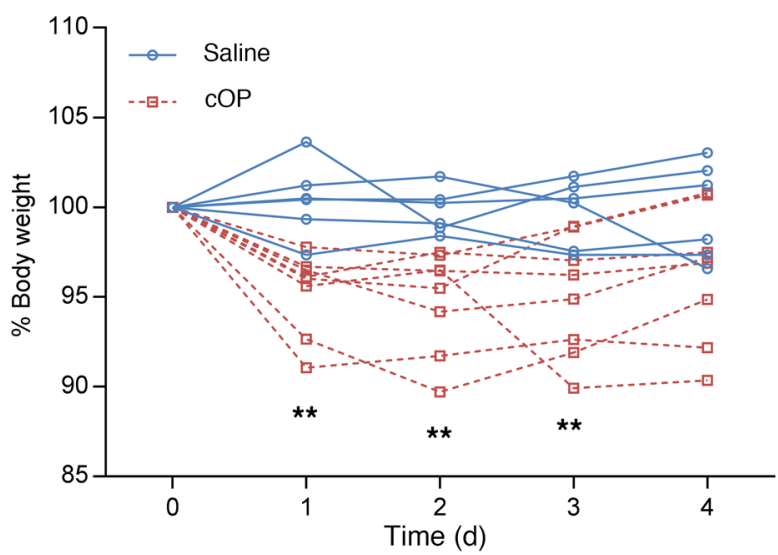


Figure 5. ODN activates POMC neurons through a GABA -independent but ODN GPCR-dependent mechanism. (A) Representative voltage-clamp whole-cell recording of a POMC neuron with or without $1 \mathrm{nM}$ ODN. (B and C) Quantification of sIPSC frequency (B) and amplitude (C) of POMC and non-POMC neurons before and during ODN application. ${ }^{*} P<0.05$ compared with control, paired Student's $t$ test, $n=5-6$ neurons from 5-6 mice. (D) Representative cell-attached recording of a POMC neuron in the presence of bicuculline, picrotoxin, cyanquixaline, and APV before and during ODN application (1 nM). (E) Quantification of AP frequency in POMC neurons with or without the inhibitors and $\operatorname{ODN}(1 \mathrm{nM}) .{ }^{*} P<0.05$ compared with inhibitors (PTX/BCC), 1-way ANOVA repeated measures with Bonferroni post hoc test, $n=10$ neurons from 10 mice. (F) Quantification of AP frequency of POMC neurons before and during $\mathrm{COP}(2 \mathrm{nM})$ application. ${ }^{*} P<0.05$ compared with control, paired Student's $t$ test, $n=6$ neurons from 4 mice. (C) Cumulative food intake in overnight-fasted (16 hours) C57BL/6 WT male mice following i.c.v. administration of $50 \mathrm{ng}$ of $\mathrm{COP}$ or saline $(n=9-10)$. (H and I) Cumulative food intake (H) and percent body weight change (I) following daily i.c.v. administration of $50 \mathrm{ng}$ of cOP or saline in ad libitum-fed $o b / o b$ mice $(n=6-8) .(\mathbf{G}-\mathbf{I}){ }^{*} P<0.05,{ }^{* *} P<0.01,{ }^{* * *} P<0.001$ compared with saline, 2-way ANOVA with Bonferroni post hoc test.

rons by endozepines derived from hypothalamic astrocytes plays a key role in feeding and body weight regulation. To our knowledge, this is the first demonstration that a gliopeptide is a key regulator of energy balance and responses to high-fat feeding. ACBP is a highly conserved protein in all eukaryotic species, found as far back as in yeast. We think that this preservation underlies the strong catabolic actions of ACBP we observe in both male and female mice on 2 genetic backgrounds.

Multiple genetic approaches allowed us to interrogate the role of ACBP in different cell types. Although we and others have reported ACBP expression in neurons $(32,48)$, ACBP is highly enriched in non-neuronal cells of the hypothalamus including ependymocytes, astrocytes, and tanycytes (31-33). Accumulating evidence suggests that tanycytes (49) and astrocytes play a key role in energy homeostasis (50). Observations of heightened susceptibility to diet-induced obesity in ACBP ${ }^{\mathrm{GFAP}} \mathrm{KO}$ mice (loss of function in astrocytes, ependymocytes, and tanycytes), but not in $\mathrm{ACBP}^{\mathrm{Nkx2} .1} \mathrm{KO}$ mice (loss of function in neurons, ependymocytes, and tanycytes), that was reversed by restoration of ACBP expression in $\mathrm{ARC} \mathrm{GFAP}^{+}$astrocytes firmly suggest that ACBP in $A R C$ astrocytes regulates energy balance. We cannot rule out that the higher residual ACBP expression in the ARC of $\mathrm{ACBP}^{\mathrm{Nkx} 2.1} \mathrm{KO}$ versus $A C B P^{G F A P} \mathrm{KO}$ mice may protect from heightened dietinduced obesity regardless of the cell type expressing ACBP. Nonetheless, this raises the question of the physiological role of ACBP in ependymocytes and tanycytes of the hypothalamus. Interestingly, pan-brain ACBP overexpression leads to hydrocephalus (enlargement of lateral ventricles) in mice, suggesting that ependymal ACBP may regulate cerebrospinal fluid production and/or circulation (51). In addition, ACBP is expressed in the subventricular zone, comprising ependymocytes, where it promotes neuroprogenitor proliferation via GABA $_{\mathrm{A}}$ inhibition $(39,52)$. Additional work and genetic models will be needed to assess specifically the role of ACBP in tanycytes.

Our findings highlight novel aspects of endozepine signaling and action in the hypothalamus. Using electrophysiology, our data suggest that ODN selectively activates ARC POMC neurons and the melanocortin system to decrease feeding and stimulate carbohydrate utilization. In addition, our results strongly suggest that ODN-induced POMC neuronal activation is independent of $\mathrm{GABA}_{\mathrm{A}}$ and involves the unidentified ODN GPCR. This concept is supported by both our $\mathrm{Ca}^{2+}$ imaging and electrophysiology data showing that CDLOP, an antagonist of the GPCR, decreased the number of ODN-responsive neurons and the intensity of $\mathrm{Ca}^{2+}$ responses in dissociated hypothalamic neurons, and reversed the activation of POMC neurons by ODN in brain slices. The notion of direct and selective activation of POMC neurons has to be taken cautiously, since we cannot rule out that ODN may affect different neuronal populations within other nuclei of the hypothalamus or extrahypothalamic areas that project onto and activate POMC neurons. Nonetheless, our data at the neuronal level are consistent with a study showing that the central anorectic effect of ODN is not affected by a GABA ${ }_{A}$ antagonist (34). Together, these findings demonstrate that ODN stimulation of the melanocortin system and inhibition of feeding are $\mathrm{GABA}_{\mathrm{A}}$-independent. However, ODN decreased GABAergic inputs in all the neurons we recorded (POMC and non-POMC), suggesting a broad impact in ARC neurons that may affect the excitability of other neuronal population(s). Further investigations will be required to characterize more precisely the effect of ODN on $\mathrm{GABA}_{\mathrm{A}}$ currents and its impact on other neurocircuits in the hypothalamus.

Consistent with previous findings (34), administration of the ODN GPCR agonist cOP centrally decreased feeding in WT mice in a manner similar to i.c.v. ODN. In addition, we found that daily administration of the agonist lowered feeding and promoted body weight loss in obese $o b / o b$ mice. Together, our results suggest that chronic stimulation of endozepine signaling, virally (Figure 2) or pharmacologically (Figure 5, H and I), exerts potent anorectic effects in mouse models of obesity.

Our findings suggest that endozepines mostly influence energy balance by reducing food intake, while increasing locomotor activity and RER. These effects are consistent with the activation of the melanocortin system (5); however, one would have expected ACBP or ODN to promote energy expenditure. It is possible that endozepines activate only a subset of POMC neurons or that higher doses may be required to affect energy expenditure.

ACBP may well exert a dual action in non-neuronal cells, as both a gliotransmitter and regulator of intracellular fatty acid metabolism. We recently showed that ACBP deficiency impairs the intracellular metabolism of unsaturated fatty acids in astrocytes (32). For this reason we cannot rule out that the unresponsiveness to the anorectic effect of central oleate and/or the obesity-prone phenotype observed in ACBP ${ }^{\mathrm{GFAP}} \mathrm{KO}$ mice may involve alterations of astrocyte fatty acid metabolism. However, the hyperphagia induced by ACBP deficiency in astrocytes is consistent with the anorectic effects induced by both i.c.v. ODN (34) (Figure 4, A and G) and viral-mediated expression of ACBP in ARC astrocytes (Figure 4, $\mathrm{L}$ and $\mathrm{M}$ ). Together, these findings provide compelling evidence that arcuate ACBP and its product ODN are anorectic gliopeptides. These findings raise the question of whether and which circulating metabolic signals stimulate the release of hypothalamic ACBP. It has been reported that glucose increases ACBP secretion in hypothalamic explants ex vivo (33). Our findings in vivo show that $\mathrm{ACBP}^{\mathrm{GFAP}} \mathrm{KO}$ mice have a normal decrease in feeding in response to leptin but a dampened anorectic response to central oleate. This 
suggests that the release of astroglial ACBP could be stimulated by oleate to in turn inhibit feeding. Additional studies will be needed to assess this hypothesis and determine whether other metabolic signals modulate ACBP release.

At the gene level, the reduced expression of $a c b p$ in the ARC in response to fasting is in agreement with recent in situ hybridization data in rats (33) and is consistent with its anorectic action. Interestingly, the diurnal expression pattern of $a c b p$ is similar to that of fatty acid-binding protein 7 (FABP7) (53), a brain-specific isoform of FABP strongly expressed in hypothalamic astrocytes (54).

While our study demonstrates the importance of ACBP in the hypothalamus, recent findings show that ACBP is expressed in glial cells of the rat brainstem, including the nucleus tractus solitarius (55), in which POMC neurons are also located. In addition, i.c.v. injection of ODN in the fourth ventricle reduces food intake (55). This raises the possibility that brainstem ACBP may reduce feeding behavior by activating POMC neurons in the nucleus tractus solitarius. However, our viral approaches targeting ARC astrocytes suggest that hypothalamic ACBP is sufficient to reduce food intake (Figure $2 \mathrm{G}$ and Figure $4 \mathrm{M}$ ). Nonetheless, the contribution of $\mathrm{ACBP}$ in different brain regions in short- versus long-term regulation of food intake and the underlying mechanisms in extrahypothalamic regions await further investigations.

More generally, it is important to mention that ACBP is expressed in several brain regions (e.g., amygdala, hippocampus) that are not commonly associated with the control of energy balance. Although the role of ACBP in these regions is still unclear, studies suggest that endogenous ACBP may play a role in social (56) and learning behavior (57). Importantly, we recently reported that astroglial ACBP deficiency does not affect anxiety in mice (31), ruling out the possibility that susceptibility to diet-induced obesity in ACBP ${ }^{\mathrm{GFAP}} \mathrm{KO}$ mice is confounded by changes in anxiety-like behavior.

Altogether, our studies demonstrate that astroglial endozepines play a key role in the hypothalamic control of energy balance. Our findings, along with a study showing that acyl-CoA binding domain-containing 7 (ACBD7, a paralog gene of ACBP) is expressed in ARC neurons and regulates feeding (58), suggest that endozepines and endozepine-like peptides are key modulators of the neurocircuits regulating energy homeostasis. These findings suggest that targeting endozepine signaling may represent a novel therapeutic avenue for obesity. More generally, our results support the emerging concept that hypothalamic astrocytes and astrocyte-derived signals play an important role in the regulation of energy balance. Undoubtedly, additional work will be required to identify the signals and pathways modulating endozepine secretion in hypothalamic astrocytes and to identify the ODN GPCR.

\section{Methods}

\section{Animals}

Experimental animals were bred under specific pathogen-free conditions on a 12-hour light/12-hour dark cycle (dark from 6:00 pm to 6:00 am). Housing temperature was maintained at $21^{\circ} \mathrm{C}\left(70^{\circ} \mathrm{F}\right)$ with free access to water and standard chow diet. Cages and water were autoclaved, and regular chow diet was irradiated. Cages were supplemented with nesting materials, and cages were changed every
2 weeks. Health status was monitored via a sentinel mouse exposed to feces from the same rack.

After genotyping (4 weeks of age), experimental mice were moved to an experimental housing room on a reverse light/dark cycle (dark cycle from 10:00 am to 10:00 pm). Mice were maintained in groups with 2-4 mice per cage until they were allocated to their experimental groups. Purchased animals were maintained in a reverse light/dark cycle for at least 10 days before starting the experimentation.

For all studies, age- and sex-matched littermates were used and individually housed in a reverse light/dark cycle unless otherwise specified. Genotype, sex, age, and number of mice are indicated for each experiment in the appropriate figure legends or section of Methods. Upon completion of the studies, mice were anesthetized with ketamine/xylazine, and blood was collected via cardiac puncture when necessary. Mice were then euthanized by decapitation before tissue collection. All mice were treatment-naive at the time of study.

$A C B P^{f / f l}$ mice were donated by Susanne Mandrup (University of Southern Denmark, Odense, Denmark) $(31,59)$ and were backcrossed at least 8 generations on the C57BL/6J genetic background (C57BL/6J, 000664). Female $A C B P^{f / f l}$ mice on the C57BL/6J background were bred with male mice expressing Cre recombinase under the mouse glial fibrillary acidic protein (GFAP) promoter [B6.Cg-Tg (Gfap-cre)73.12Mvs/J, 012886], obtained from The Jackson Laboratory. $A C B P^{+/+}$;Cre (WT), ACBP $P^{f /+} ;$ Cre (HET), and $A C B P^{f / f f}$;Cre (KO) were obtained by breeding of female $A C B P^{f / /+}$ with male $A C B P^{f / /+} ; C r e$ to obtain littermates of all genotypes. Some studies (Supplemental Figures) were performed on ACBP-KO animals (on a mixed C57BL/6J and Bom background) obtained by breeding of $A C B P^{f / f l}$ mice, on the original C57BL/6 Bom genetic background, with GFAP-Cre or Nkx2.1-Cre mice [C57BL/6J-Tg(Nkx2-1-cre)2Sand/J, 008661].

Male MC4R-KO and control wild-type (WT) mice (B6; 129S4Mc4r $\mathrm{r}^{\text {tmlLowl }} /$ J, 006414), POMC-eGFP mice [C57BL/6]-Tg(Pomc-EGFP)1Low/J, 009593], and $o b / o b$ (B6.Cg-Lep $\left.{ }^{o b} / \mathrm{J}, 000632\right)$ mice were purchased from The Jackson Laboratory (6-10 weeks old). Male POMC-eGFP hemizygous mice were bred with C57BL/6J WT females from the same genetic background to produce experimental animals.

\section{Astrocyte-specific overexpression of ACBP}

Ten- to twelve-week-old male C57BL/6J WT mice were injected bilaterally in the arcuate nucleus (ARC) as previously described (38) according to stereotaxic coordinates (from bregma: $-1.5 \mathrm{~mm}$ anteroposterior, $0.15 \mathrm{~mm}$ lateral, and $-5.9 \mathrm{~mm}$ dorsoventral from the dura) with $400 \mathrm{nl}$ per side of either control [AAV5-GFAP(0.7)-GFP, Vector Biolabs] or overexpressor [AAV5-GFAP(0.7)-mACBP-IRES-GFPWPRE, Vector Biolabs] virus at a concentration of $2.6 \times 10^{9}$ genome copies $(\mathrm{GC}) / \mu \mathrm{l}\left(1.04 \times 10^{9} \mathrm{GC}\right.$ per side) to generate WT-ARC ${ }^{\mathrm{GFP}}$ and WT-ARC ${ }^{\text {ACBP }}$ mice. Mice were allowed to recover for 1 week before the beginning of the study. Placement and efficacy of viral expression of ACBP were measured by quantitative PCR (qPCR) on ARC and ventromedial hypothalamus (VMH) microdissections. Mice that did not show at least a $10 \%$ increase in ACBP expression in the ARC compared with WT-ARC ${ }^{\text {GFP }}$ controls were excluded from the study.

\section{Astrocyte-specific rescue of ACBP}

Ten- to twelve-week-old male ACBP ${ }^{\text {GFAP }}$ WT (GFAP-Cre) and ACBP ${ }^{\text {GFAP }}$ $\mathrm{KO}$ mice were injected bilaterally in the ARC according to stereotaxic coordinates (from bregma: $-1.5 \mathrm{~mm}$ anteroposterior, $0.15 \mathrm{~mm}$ lateral, 
and $-5.9 \mathrm{~mm}$ dorsoventral from the dura) with $400 \mathrm{nl}$ per side of either control [AAV5-GFAP(0.7)-GFP, Vector Biolabs] or overexpressor [AAV5-GFAP(0.7)-mACBP-IRES-GFP-WPRE, Vector Biolabs] virus at a concentration of $2.6 \times 10^{9} \mathrm{GC} / \mu \mathrm{l}\left(1.04 \times 10^{9} \mathrm{GC}\right.$ per side $)$ to generate $\mathrm{WT}^{-A R C^{\mathrm{GFP}}}{ }^{\mathrm{KO}} \mathrm{K}-\mathrm{ARC}^{\mathrm{GFP}}$, and $\mathrm{KO}-\mathrm{ARC}^{\mathrm{ACBP}}$ mice. Mice were allowed to recover for 3 weeks before the onset of the study. Placement and efficacy of viral expression of ACBP was measured by qPCR on ARC and VMH microdissections. Mice that did not show at least a $10 \%$ increase in ACBP expression in the ARC compared with KO-ARC ${ }^{\mathrm{GFP}}$ controls were excluded from the study.

\section{In vivo studies}

High-fat diet studies. Five- to six-week old mice (ACBP ${ }^{\mathrm{GFAP}}$ and $\mathrm{ACBP}^{\mathrm{Nkx2} 2.1}$ KO, HET, and control littermates) were individually housed and fed either chow during 12 weeks or a high-fat diet (HFD) (Modified AIN$93 \mathrm{G}$ purified rodent diet with $50 \% \mathrm{kcal}$ from fat derived from palm oil; Dyets) during 16 weeks. Five- to six-week-old mice on a mixed BL/6JBom background (ACBP ${ }^{\mathrm{GFAP}}$ and $\mathrm{ACBP}^{\mathrm{Nkx} 2.1} \mathrm{KO}$, HET, and control $A C B P^{f / f l}$ littermates) were individually housed and fed with an HFD (F3282, 60\% kcal from fat, Bioserv) during 12 weeks. Body weight and food intake were measured weekly from 9:00 am to 10:00 am at the end of the light cycle. WT-ARC ${ }^{\text {GFP }}$ and WT-ARC ${ }^{\text {ACBP }}$ mice were individually housed after surgery and fed on chow. Food intake was measured weekly from 9:00 am to 10:00 am during 10 weeks starting 1 week after the surgery. WT-ARC ${ }^{\text {GFP }}$, KO-ARC ${ }^{\text {GFP }}$, and KO-ARC ${ }^{\text {ACBP }}$ mice were individually housed following surgery and fed with the HFD. Food intake was measured weekly from 9:00 am to 10:00 am during 12 weeks starting 3 weeks after surgery.

Metabolic cages. Respiratory exchange ratio (RER), energy expenditure, and locomotor activity were measured using indirect calorimetry in Comprehensive Lab Animal Monitoring System metabolic cages (CLAMS, Columbus Instruments International). Animals were single-housed in CLAMS apparatus at $21^{\circ} \mathrm{C}\left(70^{\circ} \mathrm{F}\right)$ in a dark/light cycle matching their housing conditions during 24 hours for acclimation followed by 48 hours of measurement. Energy expenditure was normalized by lean mass.

Glucose tolerance. Experimental mice were food-deprived during 5 hours with ad libitum access to water. A bolus of glucose $(1.5 \mathrm{~g} / \mathrm{kg})$ was administered via an intraperitoneal injection, and glycemia was measured from blood sampled at the tail vein using an Accu-chek Performa glucometer at T0 (before injection), 15, 30, 60, and 90 minutes. Tail vein blood samples were collected via a capillary for insulin assays.

Body composition analysis. Total fat and lean mass were assessed using a nuclear echo MRI whole-body composition analyzer. Intraperitoneal (perigonadal) and subcutaneous (inguinal) fat pads were collected and weighed using an analytical scale (Sartorius).

Intracerebroventricular cannula implantation. Male mice were anesthetized with isoflurane and placed on a stereotaxic apparatus (Kopf Instruments). Animals were implanted with a guide cannula (Plastics One) into the right lateral ventricle according to stereotaxic coordinates (from bregma: $-0.5 \mathrm{~mm}$ anteroposterior, $+1 \mathrm{~mm}$ lateral, and $-2.1 \mathrm{~mm}$ dorsoventral from the dura). Cannulated mice were allowed to recover for a week before i.c.v. administration of angiotensin II (40 ng in $2 \mu \mathrm{l})$ to verify placement. Mice that did not exhibit repeated bouts of drinking within the first 5 minutes were excluded from the study.

Intracerebroventricular injections. WT, MC4R-KO, and ob/ob male mice were separated into 2 groups. A first cohort was fasted during
16 hours starting at 5:00 pm (7 hours after the start of the dark cycle) before i.c.v. administration of either freshly reconstituted ODN (100 ng in $2 \mu \mathrm{l}$; Phoenix Pharmaceuticals) or saline at 9:00 am, 1 hour before the dark cycle. Access to food was restored 30 minutes after i.c.v. injection, and food intake was measured at 1, 2, 4, 6, 12, and 24 hours after injection. A second cohort of animals were single-housed in metabolic cages (CLAMS) during 24 hours for acclimation and were given either freshly reconstituted ODN $(100 \mathrm{ng}$ in $2 \mu \mathrm{l})$ or saline 1 hour before the onset of the dark cycle and monitored for 24 hours.

Male C57BL/6 WT mice were fasted during 16 hours starting at 5:00 pm (7 hours after the start of the dark cycle) before i.c.v. administration of either freshly reconstituted ODN receptor agonist cyclo ${ }_{1-8} \mathrm{OP}$ (cOP; 50 ng in $2 \mu \mathrm{l}$ ) prepared by standard Fmoc solid-phase peptide synthesis as previously described (44) or saline at 9:00 am, 1 hour before the dark cycle. Access to food was restored 30 minutes after i.c.v. injection, and food intake was measured at 1, 2, 4, 6, 12, and 24 hours after injection.

$o b / o b$ male mice received daily i.c.v. administration of either freshly reconstituted ODN receptor agonist cOP (34) (50 ng in $2 \mu \mathrm{l})$ or saline control at 9:00 am, 1 hour before the dark cycle, during 4 days. Body weight and food intake were measured daily.

\section{Ex vivo studies}

Electrophysiological recordings. Electrophysiological recordings were performed as previously described (42). Nonfasted 6- to 10-week-old POMC-eGFP mice [C57BL/6J-Tg(Pomc-EGFP)1Low/J, stock 009593] were intracardially perfused under anesthesia (pentobarbital $120 \mathrm{mg} /$ $\mathrm{kg}$ ) with an ice-cold oxygenated $\left(95 \% \mathrm{O}_{2} / 5 \% \mathrm{CO}_{2}\right)$ perfusion solution that contained (in $\mathrm{mM}$ ): 200 sucrose, $28 \mathrm{NaHCO}_{3}, 2.5 \mathrm{KCl}, 7 \mathrm{MgCl}_{2}$, $1.25 \mathrm{NaH}_{2} \mathrm{PO}_{4}, 0.5 \mathrm{CaCl}_{2}, 1 \mathrm{~L}$-ascorbate, and $8 \mathrm{D}$-glucose ( $\left.\mathrm{pH} 7.4\right)$. The brain was quickly removed and immersed in the same ice-cold oxygenated perfusion solution. Three $250-\mu \mathrm{m}$ coronal slices containing the ARC were performed with a vibroslice (Leica VT1000S) and placed for 1 hour at room temperature in an oxygenated recovery ACSF solution containing (in $\mathrm{mM}$ ): $118 \mathrm{NaCl}, 5 \mathrm{KCl}, 1 \mathrm{MgCl}_{2}, 25 \mathrm{NaHCO}_{3}, 1.2$ $\mathrm{NaH}_{2} \mathrm{PO}_{4}, 1.5 \mathrm{CaCl}_{2}, 5$ HEPES, 2.5 D-glucose, and 15 sucrose (osmolarity adjusted to $310 \mathrm{mOsm}$ with sucrose, $\mathrm{pH}$ 7.4). After recovery, slices were perfused with the same ACSF oxygenated media in a recording chamber placed under a microscope (Nikon EF600) outfitted for fluorescence and interference reflection-differential interference contrast (IR-DIC) videomicroscopy. Viable ARC POMC neurons were visualized with a fluorescence video camera (Nikon). For cell-attached recordings, borosilicate pipettes (4-6 M $2 ; 1.5 \mathrm{~mm}$ OD, Sutter Instrument) were filled with filtered extracellular medium. For measures of POMC neuron firing rate in response to ODN $(1 \mathrm{nM})$, action potential frequency was quantified in POMC and non-POMC neurons before (control; over the last 60 seconds before ODN application), during (1 nM ODN 3-5 minutes, over the last 60 seconds of ODN application), and after (reversal 10 minutes, over 60 seconds, 10 minutes after ODN application) ODN application at room temperature. For the measurement of POMC neuron firing rate in the presence of GABAergic inhibitors (bicuculline and picrotoxin), slices were perfused with the glutamate receptor inhibitors cyanquixaline $(20 \mu \mathrm{M})$ and D-APV $(50 \mu \mathrm{M})$ to prevent POMC neuron overexcitation (Figure 5). For the measurement of spontaneous inhibitory postsynaptic currents (sIPSCs) under whole-cell voltage-clamp recordings, pipettes were filled with a cesium chloride solution containing (in $\mathrm{mM}$ ): $140 \mathrm{CsCl}, 3.6 \mathrm{NaCl}$, 
$1 \mathrm{MgCl}_{2}$, 10 HEPES, $0.1 \mathrm{Na}_{4}$ EGTA, 4 Mg-ATP, $0.25 \mathrm{Na}-\mathrm{GTP}$ (290 mOsm, $\mathrm{pH}$ 7.3). Recordings were made using a Multiclamp 700B amplifier, digitized using the Digidata $1440 \mathrm{~A}$ interface, and acquired at $2 \mathrm{kHz}$ using pClamp 10.5 software (Axon Instruments, Molecular Devices). Pipettes and cell capacitances were fully compensated. After a stable baseline was established, $1 \mathrm{nM}$ of ODN or $2 \mathrm{nM}$ of cOP was perfused for 5-10 minutes. POMC neurons' action potential or IPSC frequency was measured over the last minute of the ODN or COP perfusion and compared with the respective frequency measured 1 minute before the perfusion.

Calcium imaging. Mediobasal hypothalamic neurons were prepared from 3- to 4-week-old Wistar rats as described previously (45). Cells were loaded with Fura-2/acetoxymethyl ester (0.5 $\mu \mathrm{M}$; Fura-2/ AM, Molecular Probes) for 20 minutes at $37^{\circ} \mathrm{C}$ in Hank's buffer balanced salt solution (containing, in mM: 25 HEPES, $121 \mathrm{NaCl}, 4.7 \mathrm{KCl}$, $1.2 \mathrm{MgSO}_{4}, 1.2 \mathrm{KH}_{2} \mathrm{PO}_{4}, 5 \mathrm{NaHCO}_{3}, 2 \mathrm{CaCl}_{2}, 2.5 \mathrm{D}$-glucose; $\mathrm{pH} 7.4$ ). Fura-2 fluorescence images were acquired every 10 seconds by alternating excitation at 340 and $380 \mathrm{~nm}$ and emissions $(420-600 \mathrm{~nm})$ with a CCD camera coupled to Live Acquisition software (TILL Photonics). Changes in intracellular calcium levels $\left(\left[\mathrm{Ca}^{++}\right]_{\mathrm{i}}\right)$ were monitored in cells held at $2.5 \mathrm{mM}$ glucose in response to ODN (1 nM) with or without the ODN receptor antagonist cyclo ${ }_{1-8}\left[\mathrm{D}-\mathrm{Leu}^{5}\right] \mathrm{OP}(\mathrm{cDLOP})(10 \mathrm{nM})$ prepared by standard Fmoc solid-phase peptide synthesis based on a previous study (44). Values for the $340 / 380 \mathrm{~nm}$ fluorescence ratio, representative of $\left[\mathrm{Ca}^{2+}\right]_{\mathrm{i}}$, were obtained after correction for background fluorescence values. Changes in $\left[\mathrm{Ca}^{2+}\right]_{\mathrm{i}}$ were quantified by calculation of the integrated area under the curve (AUC) of each ODN response with the TILL Photonics software. Neurons were considered as ODN-responsive neurons if the increase in $\left[\mathrm{Ca}^{2+}\right]_{\mathrm{i}}$ occurred between 2 and 10 minutes of treatment, had an amplitude greater than 0.2 ( $\Delta$ ratio $340 / 380$ ), lasted at least 30 seconds, and was transient. At the end of each recording, neuronal excitability was verified by measurement of $\mathrm{Ca}^{2+}$ response to $50 \mathrm{mM} \mathrm{KCl}$. Neurons not responding to $\mathrm{KCl}$ were excluded from the analysis. Analysis of each experiment was obtained from at least 3 independent cultures prepared from at least 2 animals.

Immunofluorescence. Male mice were perfused intracardially with $4 \%$ paraformaldehyde under ketamine/xylazine anesthesia. The brains were postfixed 3 hours in $4 \%$ paraformaldehyde, cryopreserved in $20 \%$ sucrose, and cryosectioned at $30 \mu \mathrm{m}$ using a sliding microtome (SM 2000R Leica). Sections were blocked and incubated with primary antibodies overnight at $4^{\circ} \mathrm{C}$ followed by 2 -hour incubation at $22^{\circ} \mathrm{C}$ with secondary antibodies. Sections were mounted and imaged with a Zeiss fluorescent microscope (Carl Zeiss AG). Primary antibodies used were anti-ACBP/DBI (1:600; DBI-Rb-Af300, Frontier Institute), anti-ACBP (1:200; polyclonal antibody; gift of J. Knudsen and S. Mandrup, University of Southern Denmark, Odense, Denmark), and anti-glial fibrillary acidic protein (1:1000; Mab360, Millipore Corp.). Secondary antibodies were Alexa Fluor 546-goat anti-rabbit IgG (A-11035) and Alexa Fluor 488-goat anti-mouse IgG (A-11001) (1:1000; Life Technologies).

Real-time PCR. Real-time PCR was performed as previously described (32). Fresh ARC microdissections that include the median eminence and the ependymal layer, or VMH microdissections, were immediately frozen on dry ice before RNA extraction using the TRIzol method (Life Technologies). RNA concentration was quantified spectrophotometrically using a NanoDrop 2000 (Thermo Fisher Scientific), and $1 \mu \mathrm{g}$ of total RNA was reverse-transcribed by M-MuLV reverse transcriptase (Life Technologies) with random hexamers following the manufacturer's conditions. The reaction mix was then diluted 5-fold before use. Quantitative gene expression was measured from 1:10 cDNA dilutions. Real-time PCR was performed using the QuantiFast SYBR Green PCR kit (Qiagen) according to the manufacturer's guidelines on a Corbett Rotor-Gene 6000. Data were analyzed using the standard curve method and normalized to actin, cyclophilin, or $18 \mathrm{~S}$ RNA expression levels.

Blood chemistry. Plasma insulin and leptin levels were measured in blood samples collected at sacrifice or during the glucose tolerance test in chow- or HFD-fed ACBP ${ }^{\text {GFAP }}$ WT and ACBP ${ }^{\text {GFAP }}$ KO male mice. Insulin and leptin assays were performed by the core metabolic phenotyping platform of the CRCHUM using commercially available ELISA kits.

\section{Statistics}

All statistical analyses were performed using GraphPad Prism software. Intergroup comparisons were performed by ANOVA with Bonferroni post hoc tests or Student's $t$ test (2-tailed) as described in the figure legends. $P$ less than 0.05 was considered significant. Data are expressed as means \pm SEM.

\section{Study approval}

All procedures using animals were reviewed and approved by the institutional animal care and use committee (Comité Institutionnel de Protection de Animaux, protocol CM16007TAs) of Centre de Recherche du Centre Hospitalier de l'Université de Montréal (CRCHUM) and the French Ministry of Research and the institutional ethics committees of Université de Bourgogne (C2EA 105) and Université de Bordeaux (C2EA 50).

\section{Author contributions}

$\mathrm{KB}, \mathrm{BT}$, and LB helped with colony management and mouse model validation and performed feeding, metabolic, qPCR, and immunofluorescence studies. CC performed $\mathrm{Ca}^{2+}$ imaging. DR performed colony genotyping, glucose tolerance testing, and i.c.v. and AAV injections. DC and ZH performed AAV injections in POMC-Cre mice. FL, HM, and XF performed electrophysiological recordings. EB synthesized the agonist and antagonist. SF and LP contributed to conceptualization and results interpretation. $\mathrm{KB}$, $\mathrm{XF}, \mathrm{SF}$, and TA analyzed results and prepared the manuscript.

\section{Acknowledgments}

We are grateful to S. Mandrup for the ACBP-floxed mice. We are thankful to A. Lefranc, L. Decocq, and A. Mathou for animal care. We thank the CRCHUM rodent metabolic phenotyping core facility for their help with CLAMS and MRI studies and the cell biology and physiology core facility for hormone assays. We thank S. Luquet (Université Paris Diderot) for insightful discussions. We are grateful to S. Audet (CRCHUM) for his help with qPCR. This work was supported by grants from the Canadian Institutes of Health Research (MOP115042 and PJT153035 to TA); the Marie Curie Foundation (CIG NeuROSenS PCIG09-GA-2011-293738 to XF); Société Francophone du Diabète and Diabète Québec (to TA); Réseau de recherche en santé cardiométabolique, diabète et obésité from Fonds de Recherche Québec-Santé (CMDO-FRQS; to TA and XF); and INSERM, Agence Nationale Recherche (ANR13-BSV4-0006 and ANR-18-CE14-0029-02 to DC, and ANR-10LABX-43 Labex BRAIN to DC and XF). HM and CC were supported by a fellowship from the department AlimH INRA and the Région Nouvelle Aquitaine (HM) or Région Bourgogne (CC). XF 
and LP were also supported by the PARI Région Bourgogne. TA, SF, and EB were supported by a salary award from FRQS. KB and BT were supported by a fellowship from Diabète Québec and LB by a fellowship from Diabetes Canada.
Address correspondence to: Thierry Alquier, CRCHUM-Pavillon R, 900 rue Saint-Denis, Montreal, Quebec H2X0A9, Canada. Phone: 514.890 .8000 ext. 23628; Email: thierry.alquier@ umontreal.ca.
1. Krashes MJ, Lowell BB, Garfield AS. Melanocortin-4 receptor-regulated energy homeostasis. Nat Neurosci. 2016;19(2):206-219.

2. Coppari R, et al. The hypothalamic arcuate nucleus: a key site for mediating leptin's effects on glucose homeostasis and locomotor activity. Cell Metab. 2005;1(1):63-72.

3. Claret M, et al. AMPK is essential for energy homeostasis regulation and glucose sensing by POMC and AgRP neurons. J Clin Invest. 2007;117(8):2325-2336.

4. Parton LE, et al. Glucose sensing by POMC neurons regulates glucose homeostasis and is impaired in obesity. Nature. 2007;449(7159):228-232.

5. Berglund ED, et al. Direct leptin action on POMC neurons regulates glucose homeostasis and hepatic insulin sensitivity in mice. J Clin Invest. 2012;122(3):1000-1009.

6. Hill JW, et al. Direct insulin and leptin action on pro-opiomelanocortin neurons is required for normal glucose homeostasis and fertility. Cell Metab. 2010;11(4):286-297.

7. Oswal A, Yeo GS. The leptin melanocortin pathway and the control of body weight: lessons from human and murine genetics. Obes Rev 2007;8(4):293-306.

8. Gourine AV, et al. Astrocytes control breathing through $\mathrm{pH}$-dependent release of ATP. Science. 2010;329(5991):571-575.

9. Pelluru D, Konadhode RR, Bhat NR, Shiromani PJ. Optogenetic stimulation of astrocytes in the posterior hypothalamus increases sleep at night in C57BL/6J mice. Eur J Neurosci. 2016;43(10):1298-1306.

10. Yang L, Qi Y, Yang Y. Astrocytes control food intake by inhibiting AGRP neuron activity via adenosine A1 receptors. Cell Rep. 2015;11(5):798-807.

11. Chen N, et al. Direct modulation of GFAPexpressing glia in the arcuate nucleus bi-directionally regulates feeding. Elife. 2016;5:e18716.

12. Douglass JD, Dorfman MD, Thaler JP. Glia: silent partners in energy homeostasis and obesity pathogenesis. Diabetologia. 2017;60(2):226-236.

13. Thaler JP, et al. Obesity is associated with hypothalamic injury in rodents and humans. JClin Invest. 2012;122(1):153-162.

14. Chari M, et al. Glucose transporter-1 in the hypothalamic glial cells mediates glucose sensing to regulate glucose production in vivo. Diabetes. 2011;60(7):1901-1906.

15. Marty N, et al. Regulation of glucagon secretion by glucose transporter type 2 (glut2) and astrocytedependent glucose sensors. JClin Invest. 2005;115(12):3545-3553.

16. García-Cáceres C, et al. Astrocytic insulin signaling couples brain glucose uptake with nutrient availability. Cell. 2016;166(4):867-880.

17. Guillod-Maximin E, Lorsignol A, Alquier T, Pénicaud L. Acute intracarotid glucose injection towards the brain induces specific c-fos acti- vation in hypothalamic nuclei: involvement of astrocytes in cerebral glucose-sensing in rats. J Neuroendocrinol.2004;16(5):464-471.

18. Kim JG, et al. Leptin signaling in astrocytes regulates hypothalamic neuronal circuits and feeding. Nat Neurosci. 2014;17(7):908-910.

19. Gao Y, et al. Disruption of lipid uptake in astroglia exacerbates diet-induced obesity. Diabetes. 2017;66(10):2555-2563.

20. Lam TK, Gutierrez-Juarez R, Pocai A, Rossetti L. Regulation of blood glucose by hypothalamic pyruvate metabolism. Science. 2005;309(5736):943-947.

21. Clasadonte J, Scemes E, Wang Z, Boison D, Haydon PG. Connexin 43-mediated astroglial metabolic networks contribute to the regulation of the sleepwake cycle. Neuron. 2017;95(6):1365-1380.e5.

22. Le Foll C, Dunn-Meynell AA, Miziorko HM, Levin BE. Regulation of hypothalamic neuronal sensing and food intake by ketone bodies and fatty acids. Diabetes. 2014;63(4):1259-1269.

23. Le Foll C, Dunn-Meynell AA, Miziorko HM, Levin BE. Role of VMH ketone bodies in adjusting caloric intake to increased dietary fat content in DIO and DR rats. Am J Physiol Regul Integr Comp Physiol. 2015;308(10):R872-R878.

24. Sweeney P, Qi Y, Xu Z, Yang Y. Activation of hypothalamic astrocytes suppresses feeding without altering emotional states. Glia. 2016;64(12):2263-2273.

25. Verkhratsky A, Matteoli M, Parpura V, Mothet JP, Zorec R. Astrocytes as secretory cells of the central nervous system: idiosyncrasies of vesicular secretion. EMBO J. 2016;35(3):239-257.

26. Yin P, Knolhoff AM, Rosenberg HJ, Millet LJ, Gillette MU, Sweedler JV. Peptidomic analyses of mouse astrocytic cell lines and rat primary cultured astrocytes. J Proteome Res. 2012;11(8):3965-3973.

27. Tokay T, et al. $\beta$-Amyloid peptide stimulates endozepine release in cultured rat astrocytes through activation of $\mathrm{N}$-formyl peptide receptors. Glia. 2008;56(13):1380-1389.

28. Loomis WF, Behrens MM, Williams ME, Anjard C. Pregnenolone sulfate and cortisol induce secretion of acyl-CoA-binding protein and its conversion into endozepines from astrocytes. J Biol Chem. 2010;285(28):21359-21365.

29. Guidotti A, Forchetti CM, Corda MG, Konkel D, Bennett CD, Costa E. Isolation, characterization, and purification to homogeneity of an endogenous polypeptide with agonistic action on benzodiazepine receptors. Proc Natl Acad Sci U S A. 1983;80(11):3531-3535.

30. Farzampour Z, Reimer RJ, Huguenard J. Endozepines. Adv Pharmacol. 2015;72:147-164.

31. Budry L, et al. DBI/ACBP loss-of-function does not affect anxiety-like behaviour but reduces anxiolytic responses to diazepam in mice. Behav Brain Res. 2016;313:201-207.

32. Bouyakdan $\mathrm{K}$, et al. A novel role for central $\mathrm{ACBP} / \mathrm{DBI}$ as a regulator of long-chain fatty acid metabolism in astrocytes. J Neurochem. 2015;133(2):253-265.

33. Lanfray D, et al. Gliotransmission and brain glucose sensing: critical role of endozepines. Diabetes. 2013;62(3):801-810.

34. do Rego JC, Orta MH, Leprince J, Tonon MC, Vaudry H, Costentin J. Pharmacological characterization of the receptor mediating the anorexigenic action of the octadecaneuropeptide: evidence for an endozepinergic tone regulating food intake. Neuropsychopharmacology. 2007;32(7):1641-1648.

35. Wang Y, Hsuchou H, He Y, Kastin AJ, Pan W. Role of astrocytes in leptin signaling. J Mol Neurosci. 2015;56(4):829-839.

36. Heinrich G, Meece K, Wardlaw SL, Accili D. Preserved energy balance in mice lacking FoxO1 in neurons of Nkx2.1 lineage reveals functional heterogeneity of FoxO1 signaling within the hypothalamus. Diabetes. 2014;63(5):1572-1582.

37. Yee CL, Wang Y, Anderson S, Ekker M, Rubenstein JL. Arcuate nucleus expression of NKX2.1 and DLX and lineages expressing these transcription factors in neuropeptide $\mathrm{Y}(+)$, proopiomelanocortin(+), and tyrosine hydroxylase(+) neurons in neonatal and adult mice. J Comp Neurol. 2009;517(1):37-50.

38. Fisette A, et al. $\alpha / \beta$-Hydrolase domain 6 in the ventromedial hypothalamus controls energy metabolism flexibility. Cell Rep. 2016;17(5):1217-1226.

39. Alfonso J, Le Magueresse C, Zuccotti A, Khodosevich K, Monyer H. Diazepam binding inhibitor promotes progenitor proliferation in the postnatal SVZ by reducing GABA signaling. Cell Stem Cell. 2012;10(1):76-87.

40. Benani A, et al. Food intake adaptation to dietary fat involves PSA-dependent rewiring of the arcuate melanocortin system in mice. J Neurosci. 2012;32(35):11970-11979.

41. Vong L, Ye C, Yang Z, Choi B, Chua S, Lowell BB. Leptin action on GABAergic neurons prevents obesity and reduces inhibitory tone to POMC neurons. Neuron. 2011;71(1):142-154.

42. Fioramonti X, Lorsignol A, Taupignon A, Pénicaud L. A new ATP-sensitive K+ channel-independent mechanism is involved in glucose-excited neurons of mouse arcuate nucleus. Diabetes. 2004;53(11):2767-2775.

43. Gandolfo P, Patte C, Leprince J, Thoumas JL, Vaudry H, Tonon MC. The stimulatory effect of the octadecaneuropeptide (ODN) on cytosolic $\mathrm{Ca}^{2+}$ in rat astrocytes is not mediated through classical benzodiazepine receptors. Eur J Pharmacol. 1997;322(2-3):275-281.

44. Leprince J, et al. Synthesis, conformationa analysis and biological activity of cyclic analogs of the octadecaneuropeptide ODN. Design of a potent endozepine antagonist. Eur J Biochem. 2001;268(23):6045-6057.

45. Chrétien C, et al. Transient receptor potential canonical 3 (TRPC3) channels are required for 
hypothalamic glucose detection and energy homeostasis. Diabetes. 2017;66(2):314-324.

46. Adamsky A, et al. Astrocytic activation generates de novo neuronal potentiation and memory enhancement. Cell. 2018;174(1):59-71.e14.

47. Cai W, et al. Insulin regulates astrocyte gliotransmission and modulates behavior. JClin Invest . 2018;128(7):2914-2926.

48. Alho H, Costa E, Ferrero P, Fujimoto M, CosenzaMurphy D, Guidotti A. Diazepam-binding inhibitor: a neuropeptide located in selected neuronal populations of rat brain. Science. 1985;229(4709):179-182.

49. Prevot V, Dehouck B, Sharif A, Ciofi P, Giacobini $\mathrm{P}$, Clasadonte J. The versatile tanycyte: a hypothalamic integrator of reproduction and energy metabolism. Endocr Rev. 2018;39(3):333-368.

50. Freire-Regatillo A, Argente-Arizón P, Argente J, García-Segura LM, Chowen JA. Non-neuronal cells in the hypothalamic adaptation to metabolic signals. Front Endocrinol (Lausanne). 2017;8:51.

51. Siiskonen $\mathrm{H}$, et al. Diazepam binding inhibitor overexpression in mice causes hydrocephalus, decreases plasticity in excitatory synapses and impairs hippocampus-dependent learning. Mol Cell Neurosci. 2007;34(2):199-208.

52. Dumitru I, Neitz A, Alfonso J, Monyer H. Diazepam binding inhibitor promotes stem cell expansion controlling environment-dependent neurogenesis. Neuron. 2017;94(1):125-137.e5.

53. Gerstner JR, Bremer QZ, Vander Heyden WM, Lavaute TM, Yin JC, Landry CF. Brain fatty acid binding protein (Fabp7) is diurnally regulated in astrocytes and hippocampal granule cell precursors in adult rodent brain. PLoS One. 2008;3(2):e1631.

54. Yasumoto Y, et al. Glial fatty acid-binding protein 7 (FABP7) regulates neuronal leptin sensitivity in the hypothalamic arcuate nucleus. Mol Neurobiol. 2018;55(12):9016-9028.

55. Guillebaud F, et al. Glial endozepines inhibit feeding-related autonomic functions by acting at the brainstem level. Front Neurosci. 2017;11:308.

56. Ujjainwala AL, Courtney CD, Rhoads SG, Rhodes JS, Christian CA. Genetic loss of diazepam binding inhibitor in mice impairs social interest. Genes Brain Behav. 2018;17(5):e12442.

57. Ujjainwala AL, Courtney CD, Wojnowski NM, Rhodes JS, Christian CA. Differential impacts on multiple forms of spatial and contextual memory in diazepam binding inhibitor knockout mice. J Neurosci Res. 2019;97(6):683-697.

58. Lanfray D, et al. Involvement of the Acyl-CoA binding domain containing 7 in the control of food intake and energy expenditure in mice. Elife. 2016;5:e11742.

59. Neess D, Bek S, Bloksgaard M, Marcher AB, Færgeman NJ, Mandrup S. Delayed hepatic adaptation to weaning in $\mathrm{ACBP}^{-/-}$mice is caused by disruption of the epidermal barrier. Cell Rep. 2013;5(5):1403-1412. 